듬 SCHOOL of GRADUATE STUDIES

EAST TENNESSEE STATE UNIVERSITY
East Tennessee State University Digital Commons@ East Tennessee State University

$12-2015$

\title{
Nurses' Perceptions of Self as Role Models of Health
}

Shelia Hurley

East Tennessee State University

Follow this and additional works at: https://dc.etsu.edu/etd

Part of the Cognition and Perception Commons, and the Nursing Commons

\section{Recommended Citation}

Hurley, Shelia, "Nurses' Perceptions of Self as Role Models of Health" (2015). Electronic Theses and Dissertations. Paper 2597. https://dc.etsu.edu/etd/2597

This Dissertation - Open Access is brought to you for free and open access by the Student Works at Digital Commons @ East Tennessee State University. It has been accepted for inclusion in Electronic Theses and Dissertations by an authorized administrator of Digital Commons @ East

Tennessee State University. For more information, please contact digilib@etsu.edu. 
Nurses' Perceptions of Self as Role Models of Health

\begin{tabular}{c} 
A dissertation \\
presented to \\
the faculty of the Graduate Program of the College \\
East Tennessee State University \\
In partial fulfillment \\
of the requirements for the degree \\
Doctor of Philosophy in Nursing \\
by \\
Shelia Hurley \\
December 2015 \\
Lisa Haddad \\
Michael Phillips \\
Soellen Edwards, Chair \\
\hline
\end{tabular}

Keywords: Role Model, Nurse, Health Promotion, Perception, Multiple Regression, Correlation Matrix, Nutrition, Smoking, Alcohol, Physical Activity, Obesity 


\author{
ABSTRACT \\ Nurses' Perceptions of Self as Role Models of Health \\ by \\ Shelia Hurley
}

Given the sad state of obesity and lifestyle-related illnesses in the US, nurses, as the largest and most trusted health profession, must take the cause of health promotion seriously and personally. This study seeks to close the gap in knowledge of nurses' perception of self as a role model of health and personal healthy lifestyle behaviors. This study focuses on four specific behaviors that lead to a healthy lifestyle: limit alcohol, avoid tobacco, improve nutrition, and engage in physical activity. The purpose of this study is to determine the relationship between nurses' health practices and their perceptions of self as role models for health promotion using constructs of the Social Cognitive Theory. The final sample consisted of 804 registered nurses in the state of Tennessee. In this study, $4 \%$ report smoking, $24.9 \%$ drink alcohol, $34 \%$ are overweight and $30 \%$ obese. Approximately $70 \%$ do not meet the weekly physical activity recommendations of 150-minutes and $32.8 \%$ follow guidelines for a healthy diet only $50 \%$ of the time or less. There was a significant correlation between following a healthy diet or physical activity and the Self as a Role Model of Health Promotion (SARMHEP) scores. Based on the regression analysis, working in an acute care or ambulatory setting negatively affected the SARMHEP, as opposed to age and gender having a positive effect on the SARMHEP score. This study has the potential to provide key information that can be used to promote health among nurses. 
Copyright 2015 by Shelia Hurley

All Rights Reserved 


\section{ACKNOWLEDGEMENTS}

I would like to thank the many supporters that made this dissertation possible. First, my dissertation chair, Dr. Joellen Edwards, for her vision, insight, and dedication that inspired my focus, guided my decisions, and encouraged my persistence to complete the dissertation process. I would like to thank my dissertation committee members: Dr. Sharon Loury, Dr. Lisa Haddad, and Dr. Michael Phillips for their invaluable insights, expertise, attention to detail, and support to enhance my study. I would also like to thank Dr. Jann Cupp for his continued mentoring and assistance in analyzing my data. To my new friend whom I met on the first day of class, Jean Bernard, I thank for her encouragement and perseverance. I was blessed to have her throughout the process to laugh, cry, or pray as the situation warranted. To Ann Hellman, a longtime friend and colleague, that encouraged me to get this degree and continues to provide much support and influence in my life. And last, but not least, my family. My husband, Jason, has been provided encouragement, technical support, and love. And my children, Lillian, Preston, Austin, and Alaina, have provided encouragement and love this process. 


\section{TABLE OF CONTENTS}

Page

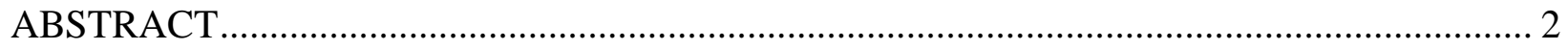

ACKNOWLEDGEMENTS ......................................................................................... 4

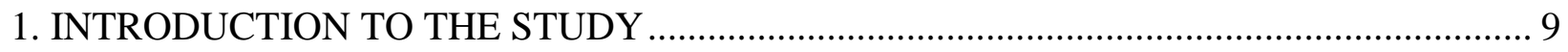

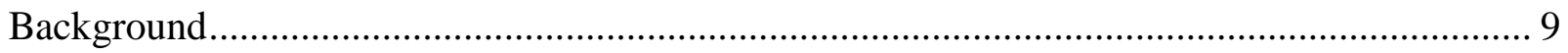

Nurses as Role Models .......................................................................................... 12

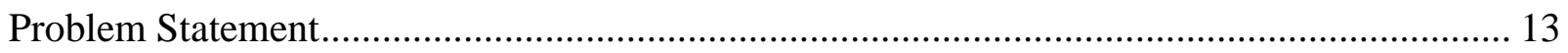

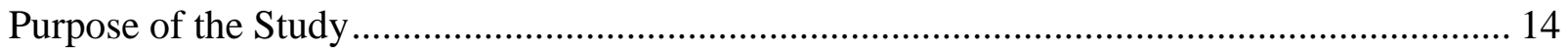

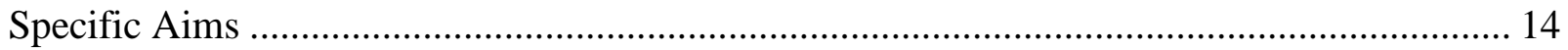

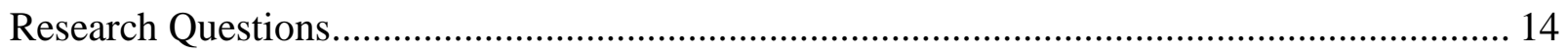

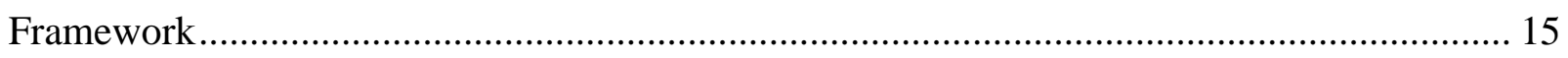

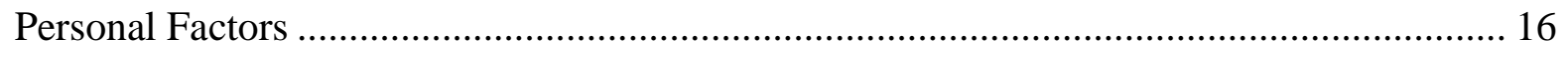

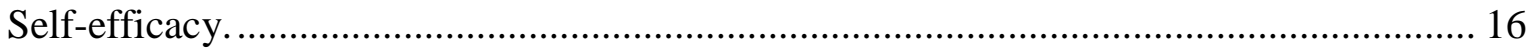

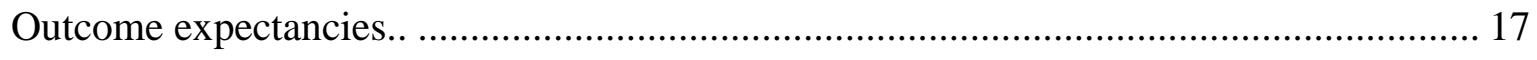

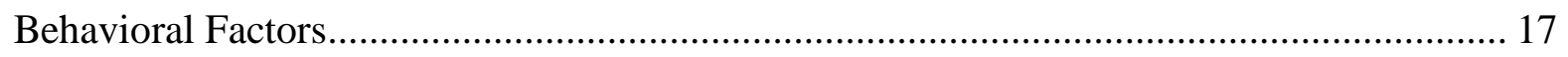

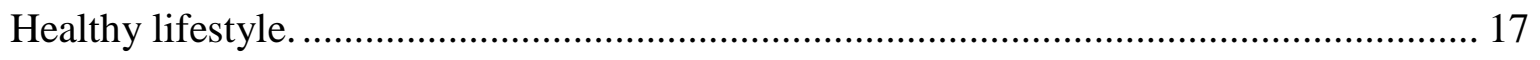

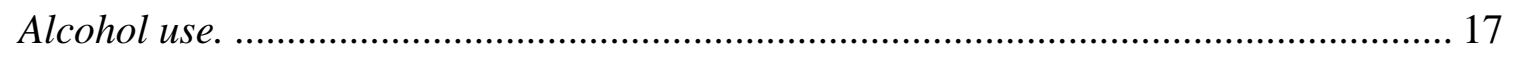

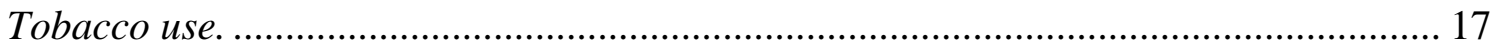

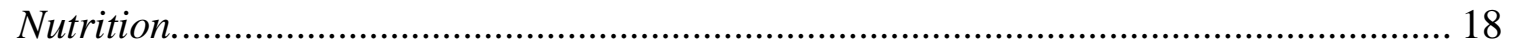




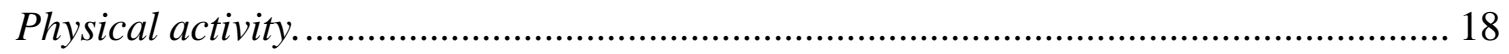

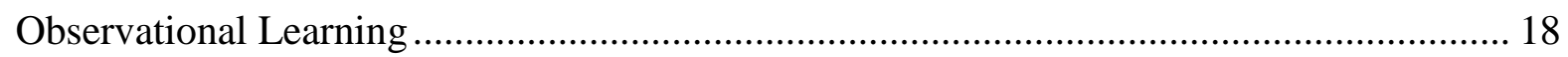

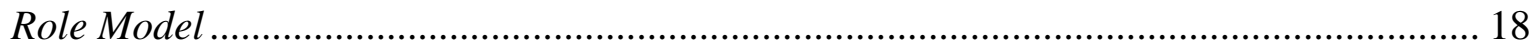

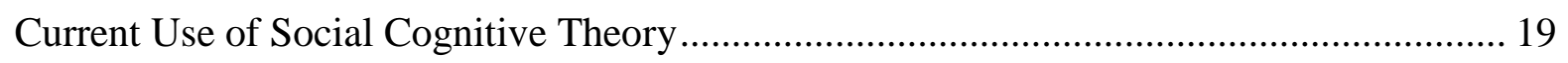

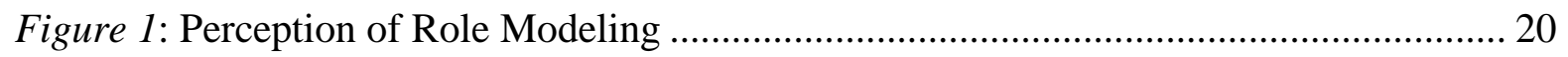

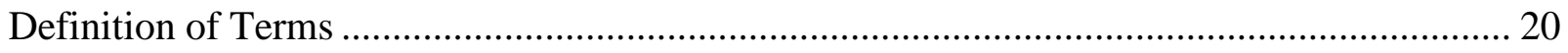

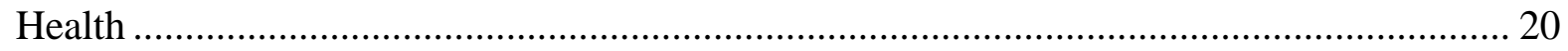

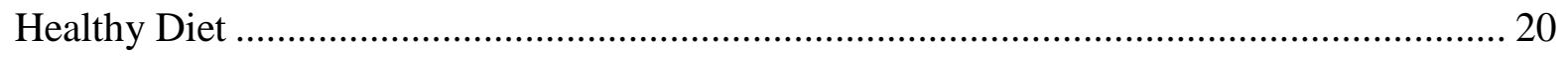

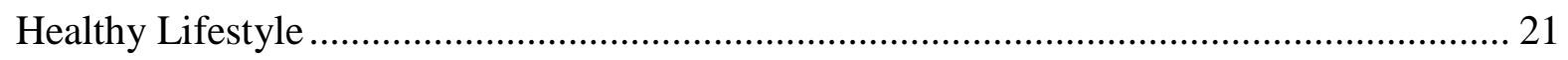

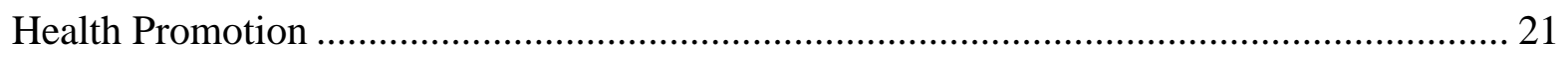

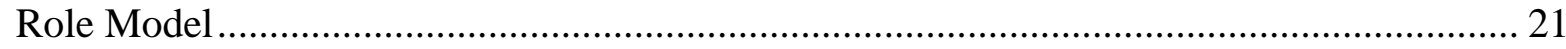

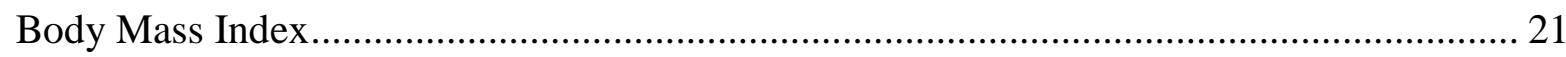

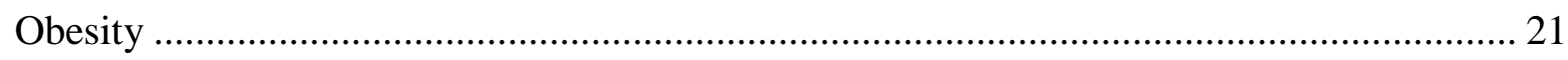

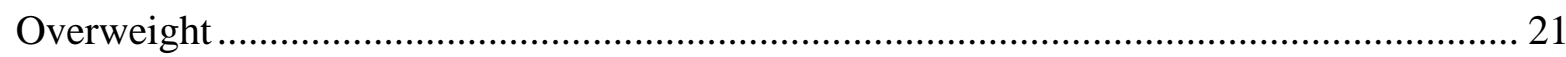

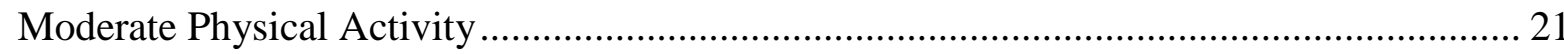

Vigorous Physical Activity ……………………………............................................... 22

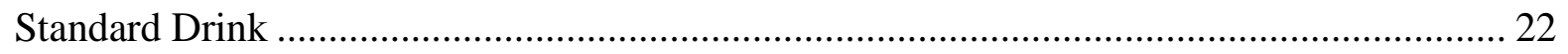

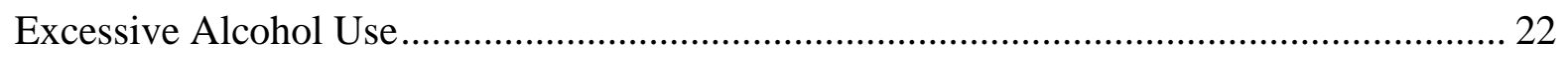

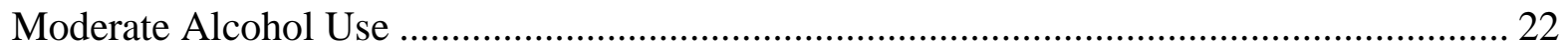

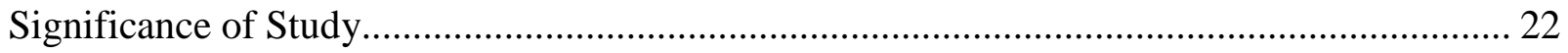




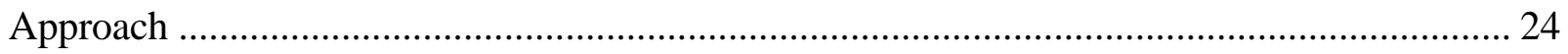

Factors Affecting Health of the US Population................................................................ 25

Nurses as Role Models of Health ................................................................................... 28

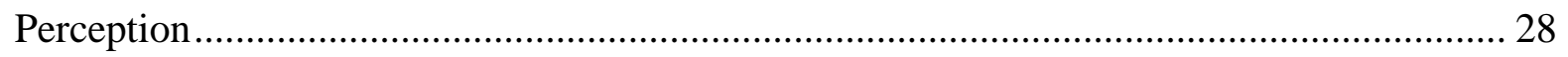

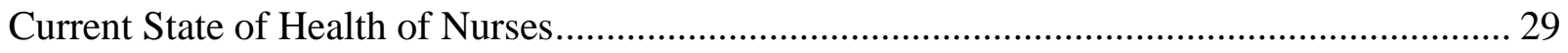

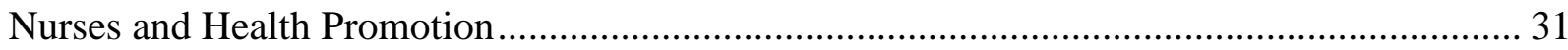

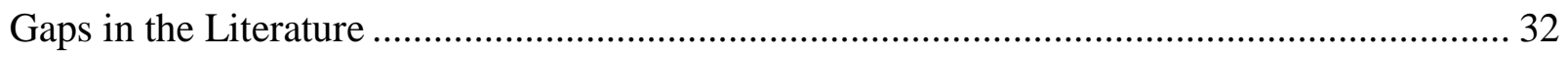

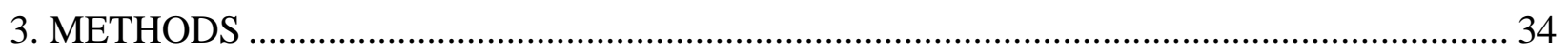

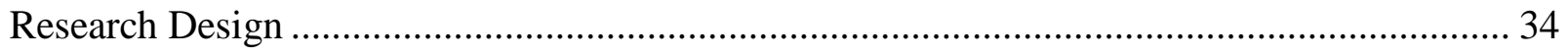

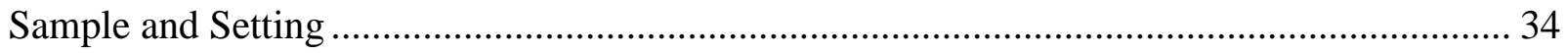

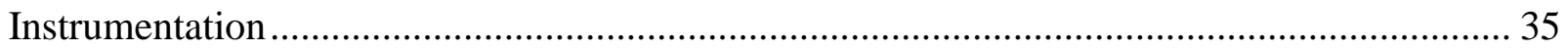

Self as Role Model for Health Promotion ..................................................................... 35

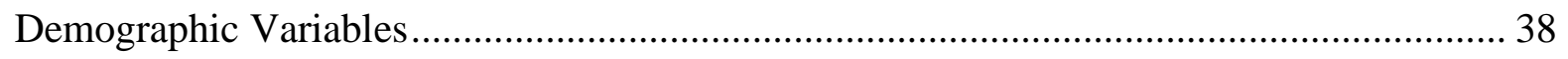

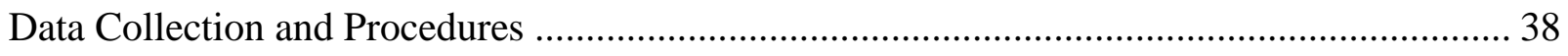

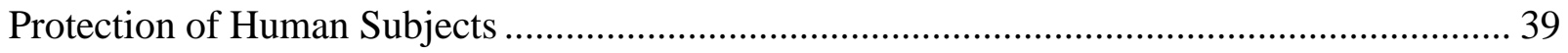

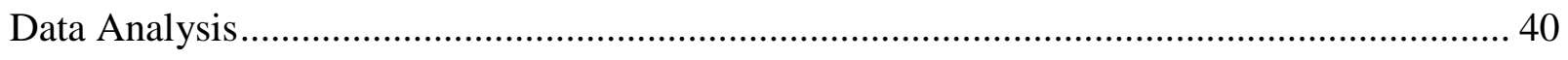

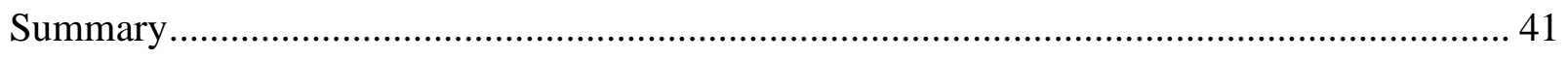

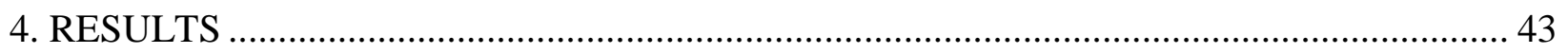

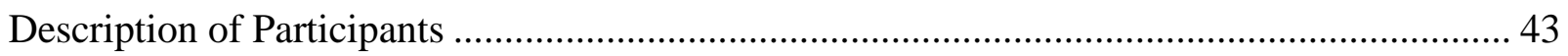




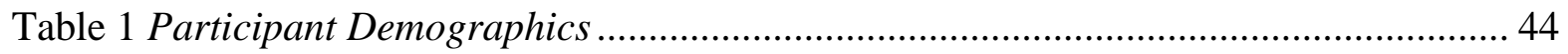

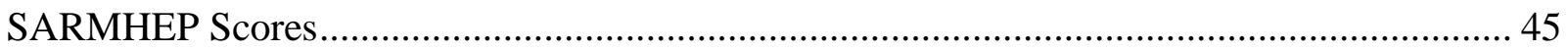

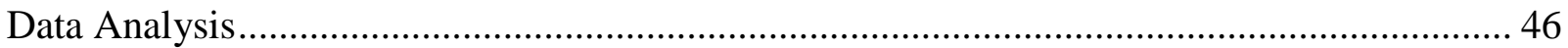

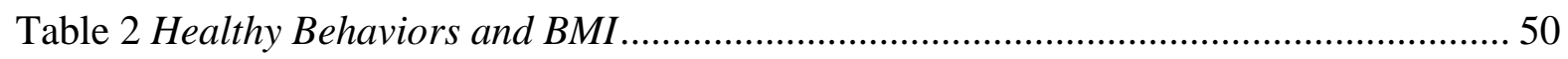

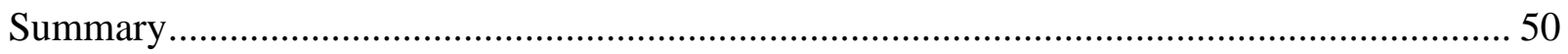

5. DISCUSSION, IMPLICATIONS AND RECOMMENDATIONS ................................... 52

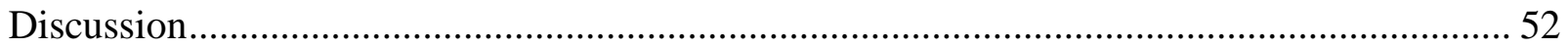

Table 3 Tennessee Nurses and National Data Comparison ............................................ 55

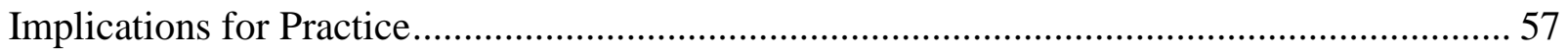

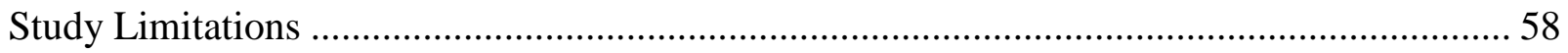

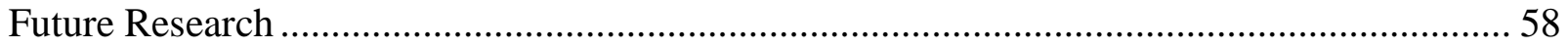

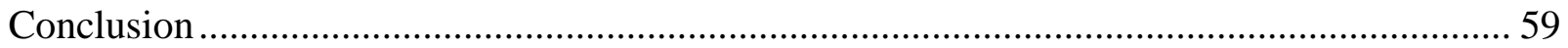

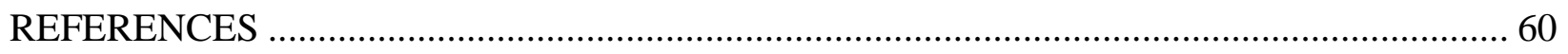

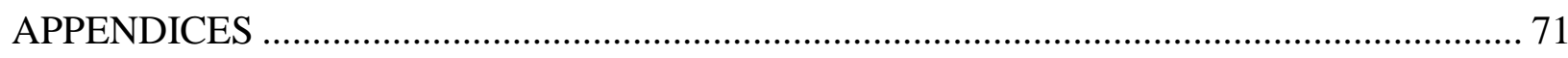

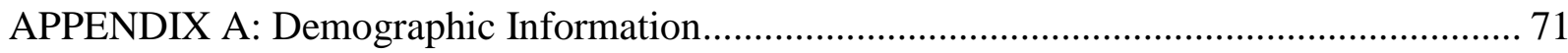

APPENDIX B: The Self as Role Model in Health Promotion ........................................... 74

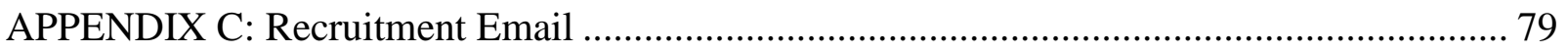

APPENDIX D: Recruitment Reminder Email .......................................................... 80

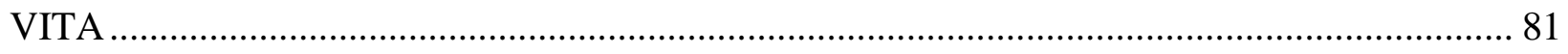




\section{CHAPTER 1}

\section{INTRODUCTION TO THE STUDY}

Nurses are the nation's largest group of healthcare professionals and are uniquely positioned to serve as effective and convincing models of healthy behaviors in their role as resources for health promotion. As role models, nurses should personally value health and help to shape society's value of health through education, teaching, role modeling and health policy; however, it is not clear if nurses associate their personal health with their professional role as a health promoter. It is known that healthcare professionals play an important role in promoting health to the population (Borchardt, 2000; Cipriano, 2013; Denehy, 2003; Popplewell, 2006). As healthcare costs and mortality rates related to preventable diseases caused by smoking and obesity continue to rise, unhealthy behaviors such as poor nutrition, inadequate physical activity and smoking can be reduced through health promotion. The Centers for Disease Control (CDC) focuses on four specific behaviors that lead to a healthy lifestyle: limit alcohol, avoid tobacco, improve nutrition, and engage in physical activity (2011a). This study will examine nurses' perceptions of role modeling health promotion in relation to their own healthy lifestyle behaviors.

\section{Background}

The World Health Organization (WHO) defines health as "a state of complete physical, social, and mental well-being, and not merely the absence of disease or infirmity" (2003, para. 1). Along with this definition, in 1996, Nola Pender defined health as a "dynamic state not merely the absence of disease" (p. 6). From these definitions, it is clear that health is a multidimensional state. The WHO first defined the term health promotion in 1986 for the First International Conference on Health Promotion. According to WHO (1986) health promotion is 
the progression of empowering others to improve their health. In 1996, Pender described health promotion as an action inspired by the aspiration to increase the potential for health and wellness. Pender's definition focused more on the individual and their behavior in her health promotion model; however she was able to include the complexity of the social environment, interpersonal environments, and the interaction of the individual with the environment.

The term health promotion is often used in place of strategies and interventions that carry out health promoting activities. For example, health promotion is often used interchangeably with the terms health education, health behaviors, preventive health care, and clinical health promotion (Blake, Malik, Mo, \& Pisano, 2011; Casey, 2007; Whitehead, 2001). This causes confusion among professionals as to their roles in health promotion. While the term continues to evolve, it is evident that the focus of health promotion is to positively impact the health of individuals and communities. Clearly, health promotion is multidimensional and requires a multidimensional approach including strategies and interventions to increase knowledge and improve attitudes, skills and behaviors.

The definition of a healthy lifestyle has evolved over the last 45 -years years since health promotion became more prevalent in prevention of disease. Over time, research has shown that healthy lifestyle behaviors lead to improved health. Lifestyle modification significantly improves risk of heart disease, cancer, respiratory disease, stroke, diabetes, and obesity (Dworetzky, Bromfield, Townsend, \& Kang, 2010; Grabowska \& Narkiewicz, 2013; Liu et al., 2012). Research shows change to modifiable behaviors such as to stop smoking, limit alcohol, improve nutrition, and increase physical activity improve overall health of an individual (CDC, 2011a).

Smoking was once socially accepted and even glamorized in movies by celebrities. Society looked to celebrities as role models. Now smoking receives much publicity as a 
behavior that causes harm to self and others. Research shows that smoking leads to cancer, lung disease and vascular disease (CDC, 2015a; 2015b). Smoking currently contributes to more than 480,000 deaths (CDC, 2015b). Now legislation prohibits smoking in most public places, restricts advertising and taxes the sale of tobacco (CDC, 2011b).

The history of alcohol use includes medicinal purposes, social and cultural events, and relaxation. Alcohol use is very common in our society and is the third leading lifestyle-related cause of death (CDC, 2014c). Alcohol use is controversial because it is linked to violence, disease and accidents (CDC, 2014c). However, research has shown that alcohol use in moderation offers some health benefits such as reduced risks of stroke, cardiovascular disease, and obesity (Poli et al., 2013). Some research indicates that abstaining from alcohol increases the risk of hypertension, metabolic syndrome, and obesity (Poli et al., 2013).

The American diet is now one of convenience. After World War II and the increase of national highways provided easier transportation of goods, the nation saw an increase in prepackaged foods and fast food restaurant chains (Cordain et al., 2005). Over the past 45 -years years, research indicates an increase in the amount of sugar, fat and total calories consumed by the American people (Smith, Ng, \& Popkin, 2013). Even as manufacturers found ways to produce low-fat, low sugar foods with the addition of substitutes, the weight of the American people continued to rise (CDC, 2014b; Smith et al., 2013). Current dietary recommendation are to eat more fruits, vegetables, whole grains, seafood; and choose fat-free and low-fat dairy while decreasing salt and foods high in sodium, saturated fats, trans fats, cholesterol, added sugar, and refined grains (Health.gov, 2014).

At the same time that fat, sugar and calories increased, American jobs became more sedentary (Church et al., 2011; Cordain et al., 2005). The decrease of physical activity 
contributes to stroke, cardiovascular disease, diabetes, cancer, depression and obesity (CDC, 2014b). Less than half the US population meets the recommended physical activity which results in increased disease and healthcare costs (CDC, 2014d). According to the CDC adults age 18 to 64 need moderate physical activity of at least 150-minutes of moderate exercise such as brisk walking spread over at least five days each week, or on three days a week or more; and muscle strengthening exercise on at least 2 days a week; or a total of 75 minutes of vigorous exercise each week such as jogging or race walking and muscle strengthening exercise on at least 2 days a week to positive impact health (2014d). Even with these recommendations on diet and exercise, obesity rates are increasing. The Trust for America's Health and Robert Wood Johnson Foundation (RWJF), reported a significant increase over the last year in obesity in six states: Alaska, Delaware, Idaho, New Jersey, Tennessee and Wyoming (2014). Obesity rates are an implication of poor diet and inadequate physical activity which lead to poorer health across the nation.

\section{Nurses as Role Models}

Robert K. Merton created the term "role model" from previous work done with reference groups, and he describes healthcare professionals as a standard frame of reference to which others compare themselves (Holton, 2004). According to Bandura's (1977) Social Learning Theory behaviors are learned by observing others; the values and beliefs of the role model are adopted by the learner. The literature provides a number of definitions and interpretations for role modeling, but widely acknowledges that role modeling can promote adoption of observed behaviors or attitudes in either positive or negative circumstances (Cruess, Cruess, \& Steinert, 2008; Perry, 2009). 
Role modeling in health is currently represented in the literature predominantly related to health professionals' demonstration of healthy behaviors for the community (Blake et al., 2011; Yancey, Grant, Kurosky, Kravitz-Wirtz, \& Mistry, 2011). The American Nurses Association (ANA) defines a healthy nurse as "one who actively focuses on creating and maintaining a balance and synergy of physical, intellectual, emotional, social, spiritual, personal and professional wellbeing" (2014, para. 1). The ANA discusses the potential impact of healthy nurses who live "life to the fullest capacity, across the wellness/illness continuum, as they become stronger role models, advocates, and educators, personally, for their families, their communities and work environments, and ultimately for their patients" (2014, para. 1). The Essentials of Baccalaureate Education produced by the American Association of Colleges of Nursing (AACN, 2008) state that the baccalaureate nurse is expected to engage in self-care in an effort to better care for others. According to the ANA and AACN, the nurse is or should be a role model of health. Therefore, nurses' own health behaviors and attitudes as they role model for clients, students, and the community are especially important.

\section{Problem Statement}

Although literature contains accounts of nurses that do not practice or promote healthy behaviors, very little is known empirically about nurses' perception of self as role models for health promotion in relation to their health practices. It is not clear if nurses' perception of their personal health correlates to their professional role as a health promoter. This study fills this knowledge gap through the examination of nurses' perception of self as role models of health promotion, and the correlation of that perception with personal health behaviors. 


\section{Purpose of the Study}

The purpose of this study is to determine the relationship between nurses' health practices and their perceptions of self as role models for health promotion. This study is designed to provide a broadly based evaluation of healthy behaviors currently used by nurses and the relationship of those behaviors to perception of self as a role model of healthy behavior to clients and the community.

\section{Specific Aims}

The specific aims of this study are to examine the extent to which nurses participate in healthy behaviors, to determine if a relationship exists between what nurses' believe in regards to

healthy behaviors and what they actually do, to determine if nurses perceive the role modeling of appropriate physical activity, healthy eating, smoking behaviors, and alcohol intake as important to their clients and community, and to raise awareness among nurses of the need to practice and promote healthy behaviors.

\section{Research Questions}

1. Is there a relationship between perception of self as a role model of healthy behaviors as measured by the Self as a Role Model of Health Promotion (SARMHEP) scores and personal health behaviors reported in the demographics?

2. To what extent do practice settings, educational preparation, years of practice experience, race and ethnicity, gender, age, region and type of community contribute to perception of self as a role model of healthy behaviors as measured by SARMHEP scores? 
3. To what extent do practice settings, educational preparation, years of practice experience, race and ethnicity, gender, age, region and type of community contribute to smoking as reported in the demographics?

4. To what extent do practice settings, educational preparation, years of practice experience, race and ethnicity, gender, age, region and type of community contribute to alcohol use as reported in the demographics?

5. To what extent do practice settings, educational preparation, years of practice experience, race and ethnicity, gender, age, region and type of community contribute to healthy diet as reported in the demographics?

6. To what extent do practice settings, educational preparation, years of practice experience, race and ethnicity, gender, age, region and type of community contribute to physical activity as reported in the demographics?

7. To what extent do Tennessee nurses report healthy personal behaviors?

\section{Framework}

The framework for this study is based on the theoretical underpinnings of the Social Cognitive Theory (SCT). The emphasis of the SCT is the cognitive processes that motivate people to use capabilities for personal and social improvement (Davidson Films, 2003). The theory analyzes the thought, motivation and action of human behavior through key constructs of self-efficacy, outcome expectancies, and observational learning (Bandura, 1986, \& 2001). The SCT key concepts include self-perception, reciprocal determinism, observational learning, and that individuals are both products and producers of their environment (Bandura, 2001). The SCT proposes that each factor in the individual characteristics and experiences area and the behavior 
specific cognitions and affect area has a direct influence on health promoting behavior. SCT views behavioral change as occurring within the context of larger social structures.

This framework is derived from SCT based on the concepts of personal factors (e.g., selfefficacy and outcome expectancies), environmental factors (e.g., perception of role modeling), behavior (e.g., living a healthy lifestyle) and the reciprocal behavior (see Figure 1). The variables self-perception of role-modeling health behaviors are measured using the Self as a Role Model of Health Promotion (SARMHEP). The SARMHEP also includes subscales that measure selfefficacy and outcome expectancies. Healthy lifestyle practices are addressed in the demographics to address the four areas previously defined that contribute to health: limit alcohol, avoid tobacco, improve nutrition, and engage in physical activity. This framework provides constructs to explain the relationship between the nurses' self-perception as a role model and their health promoting behaviors and healthy lifestyle choices.

\section{Personal Factors}

Self-efficacy. Self-efficacy is a primary concept in the theory that reveals the individual's beliefs about their ability to achieve a task successfully. As an individual's own cognitive process has an effect on their environment, self-efficacy plays an important role in this triadic reciprocal causation model. The actions taken may be positive, negative, or neutral. An alteration of one factor affects another factor (Bandura, 1977).

Conceptual definition: As the foundation of human motivation, self-efficacy consists of the mastery of experiences, social modeling, social persuasion, and the ability to read their own physical and emotional states to modify their behavior to result in the attainment of goals and influences personal choices (Bandura, 2001). 
Operational definition: Individual's scores on the SARMHEP subscales (use of professional self, use of imperfect self, valuing self, and self as health promoter).

Outcome expectancies. Conceptual: Outcome expectancies are the belief that a behavior will lead to a specific outcome (Bandura, 2001). The environment (e.g, social models) influences outcome expectancies.

Operational: Individual's scores on the SARMHEP subscale identification of self with the idealized.

\section{Behavioral Factors}

Healthy lifestyle. Conceptual: In this study, a healthy lifestyle is defined based on four behaviors: limit alcohol to moderate use, avoid tobacco, improve nutrition, and engage in moderate physical activity (CDC, 2011a).

Operational: A healthy lifestyle is measured in the individual's self-report on the demographic questionnaire in each area.

Alcohol use. Conceptual: The act of drinking a standard drink that contains 0.6 ounces

of pure alcohol, for example, 12-ounces beer, 80-ounces malt liquor, 5-ounces of wine, or 1.5 ounces of 80-proof distilled spirits (U.S. Department of Agriculture and U.S.

Department of Health and Human Services, 2010).

Operational: The individual's self-report in the demographic questionnaire to the amount of drinks each day.

Tobacco use. Conceptual: The act of smoking tobacco in the form of cigarettes.

Operational: The individual's self-report in the demographic questionnaire to the amount of cigarettes smoked each day. 
Nutrition. Conceptual: A healthy diet is defined as eating more fruits, vegetables, whole grains, seafood, and choosing fat-free and low-fat dairy while decreasing salt and foods high in sodium, saturated fats, trans-saturated fats, cholesterol, added sugar, and refined grains (CDC, 2011a).

Operational: The individual's self-report in the demographic questionnaire as to how faithfully guidelines are followed for a healthy diet on a scale of 1-10.

Physical activity. Conceptual: Moderate exercise such as brisk walking spread over at least five days each week, or on three days a week or more (CDC, 2014d).

Operational: The individual's self-report in the demographic questionnaire as to how many minutes in participation of moderate exercise.

\section{Observational Learning}

A core premise of the SCT is that people learn through observation of others. Bandura (1977) described this learning as vicarious learning or modeling because learning occurs through observation of the behavior in the environment. The learner may also inhibit their participation in a behavior if the learner observes a model suffers consequences. For example, if a client perceives the health promoter to be unhealthy, the client may choose not to follow their advice about health promotion. As the viewer observes a role model, formations of their own views of reality transpire. The role model is influential in shaping these views of reality. Social learning through observation forms beliefs, values, and expectations based on an individual's perception.

\section{Role Model}

Conceptual: A role model is defined as someone that provide examples of behavior to observe and imitate (Bandura, 1977). 
Operational: The individual's self-report in the Self as a Role Model of Health Promotion questionnaire.

\section{Current Use of Social Cognitive Theory}

Research suggests that factors included in the SCT account for much of the variance in a variety of health behaviors, including smoking cessation (McKenna et al., 2001; Movsisyan et al., 2012; Willaing \& Ladelund, 2004), nutrition (Boaz et al., 2013; Buxton \& Davies, 2013; Malik, Blake, \& Batt, 2011), physical activity (Casey, 2007; Gance, Sidora, Keesing, Gottesman, \& Brady, 2009) and alcohol use (Sharma, 2005). The result of these studies are used to understand and intervene in health behaviors by incorporating knowledge from multiple disciplines. In addition, SCT has been used to understand the practice of nursing (Perry, 2009) and to encourage nurses to role model healthy behaviors (Borchardt, 2000). 


\section{Perception of role modeling}

health behaviors
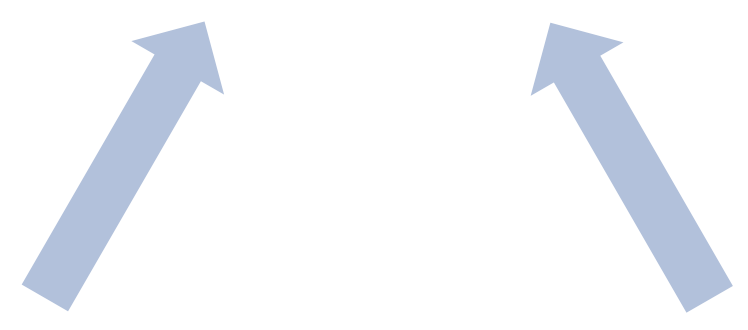

Personal factors

(Self-efficacy,

outcome expectations,

demographics)
Behavioral factors

(Nutrition

Physical Activity

Alcohol Use

Tobacco Use)

Figure 1: Perception of Role Modeling

\section{Definition of Terms}

\section{Health}

For this study, the WHO definition is used to define health: "a state of complete physical, social, and mental well-being, and not merely the absence of disease or infirmity" (2003, para. 1).

\section{Healthy Diet}

A healthy diet is defined as eating more fruits, vegetables, whole grains, seafood, and choosing fat-free and low-fat dairy while decreasing salt and foods high in sodium, saturated fats, trans-saturated fats, cholesterol, added sugar, and refined grains (CDC, 2011a). 


\section{Healthy Lifestyle}

In this study, a healthy lifestyle is defined based on four behaviors: limit alcohol to moderate use, avoid tobacco, improve nutrition, and engage in moderate physical activity (CDC, 2011a).

\section{Health Promotion}

The process of empowering others improve their health through education, access and modeling (WHO, 1986; Pender, 1996).

\section{Role Model}

A role model is someone that provide examples of behavior to observe and imitate (Bandura, 1977).

\section{Body Mass Index}

A body mass index (BMI) is the ratio for weight to height. This is a simple calculation and creates a standardized measurement by which obesity can be measured (CDC, 2014a).

\section{Obesity}

Obesity can be defined as a BMI of greater than 30 (CDC, 2014a).

\section{Overweight}

The CDC defines overweight as a BMI of greater than 25 (CDC, 2014a).

\section{Moderate Physical Activity}

Moderate physical activity is defined as a target heart rate 50 to $70 \%$ above the individual's maximum heart rate (CDC, 2014d). Examples of moderate activity include brisk walking and water aerobics (CDC, 2014d). 


\section{Vigorous Physical Activity}

Vigorous physical activity is defined as a target heart rate 70 to $85 \%$ above the individual's maximum heart rate (CDC, 2014d). Examples of vigorous physical activity include jogging or race walking and swimming (CDC, 2014d).

\section{Standard Drink}

A standard drink contains 0.6 ounces of pure alcohol, for example, 12-ounces beer, 80ounces malt liquor, 5-ounces of wine, or 1.5 ounces of 80-proof distilled spirits (U.S. Department of Agriculture and U.S. Department of Health and Human Services, 2010).

\section{Excessive Alcohol Use}

Excessive alcohol use is defined as more than eight drinks a week for women and more than 15 drinks a week for men (CDC, 2011a).

\section{Moderate Alcohol Use}

Moderate alcohol use is defined as one drink a day for women and two drinks a day for men (CDC, 2011a).

\section{Significance of Study}

Nurses' role modeling for health promotes credibility in the public and increases the likelihood of positive change in the patient (Blake \& Chambers, 2011; Illingworth, 2006). Nurses are in a position to promote and role model health; however the literature suggests that nurses struggle with promoting health to patients when their own health behaviors are poor. Nurses that practice healthy lifestyle behaviors are found to positively influence teaching healthy behaviors to patients. To fulfill their optimal professional role, nurses must promote health through their own lifestyle choices and evaluate their self-perception as role models of healthy behaviors. Given the sad state of obesity and lifestyle-related illnesses in the US, nurses, as the largest and 
most trusted health profession, must take the cause of health promotion seriously and personally. This study seeks to close the gap in knowledge of nurses' perception of self as a role model of health and personal healthy lifestyle behaviors. 


\section{CHAPTER 2}

\section{REVIEW OF THE LITERATURE}

\section{Approach}

The integrative research review described in this paper began with a focus on studies using the key terms "health promotion," "role modeling," "nurses," "role modeling and nurse," "healthy behaviors," and "healthy nurses" in the databases of Cumulative Index to Nursing and Allied Health Literature (CINAHL), Health Source Consumer edition, Nursing and Allied Health, Health Source Nursing/Academic edition, ProQuest, EBSCOhost, and PsycINFO with limiters including English only, full text, and peer reviewed. These databases were considered appropriate because they use sources that relate to nursing, allied health, and health promotion. A priori inclusion criteria consisted of literature that used nurses or nursing students as the population to identify the state of health of nurses, their personal beliefs, or their lifestyle practices. The initial search yielded 8,832 articles. To narrow the search further, dates were limited to the years 2000 to 2014 because prior studies focused on health education instead of health promotion. In addition, a combination of the terms identified articles that centered on the role of nurses as role models in health promotion or their health beliefs and practices. Research with nursing students in the same context was included. Studies focusing on nurses as role models of health promotion in contexts unrelated to smoking, nutrition, physical activity, or obesity were excluded. An ancestral review allowed inclusion of additional pertinent information. The narrowed search identified 265 articles for review. A total of 35 articles overlapped in more than one database. An in-depth review of 105 articles based on the inclusion criteria provided a final total of 51 articles. The data was entered into Microsoft Access to organize and analyze pertinent information. Of the final 51 articles, 29 were based on 
quantitative methodology, including one dissertation; five were based on qualitative inquiry; four used a mixed methods design; four were literature reviews and the remaining nine articles were anecdotal.

\section{Factors Affecting Health of the US Population}

Leading cause of deaths in the US are heart disease, cancer, respiratory disease, stroke, and diabetes (CDC, 2015a). These causes are attributed to modifiable lifestyle behaviors. According to the CDC (2011a), four factors that link to a healthy lifestyle are to stop smoking, improve nutrition, engage in physical activity, and use alcohol moderately. The following section will address health related to smoking, nutrition, physical activity and moderate alcohol use.

Health care costs continue to rise with an estimated $\$ 300$ billion each year related to smoking (CDC, 2015b). Smoking is related to cancer, heart disease, stroke, lung disease and diabetes (CDC, 2015b). While cigarette smoking is still the leading cause of preventable death in the United States and accounted for more than 480,000 (20\%) deaths annually, $18 \%$ of the U.S. population continues to smoke (CDC, 2011b), posing a serious threat to personal health and adding cost to health care delivery systems.

Health care costs are also on the rise for obesity-related conditions with an estimate of $\$ 147$ billion each year including heart disease (CDC, 2014b). Other obesity related conditions include diabetes, cancer and stroke. Obesity-related preventable diseases account for over 300,000 deaths each year (West Virginia Department of Health and Human Resources [WV DHHR], n.d.). The CDC reports $33.9 \%$ of the population is overweight and $35.1 \%$ is obese (2014b). Obesity is often used as a measure of health status, and is a clear indicator of risk for preventable morbidity and mortality. 
Obesity related conditions can be directly related to poor nutrition and lack of physical activity (CDC, 2014a). According to the CDC (2009) only 14\% of the nation's adults consume more than two fruits and three vegetables each day. Less than half the US population meet the recommended physical activity which results in increased disease and healthcare costs (CDC, 2014d). In 2014, the Trust for America's Health and RWJF, reported a significant increase in obesity over the past year in six states: Alaska, Delaware, Idaho, New Jersey, Tennessee and Wyoming.

Tennessee is rated fourth in the nation in adult obesity at $33.7 \%$ which is an increase from 25.6 in 2004 (Trust for America's Health and RWJF, 2014). West Virginia and Mississippi have the highest rates of obesity at $35.1 \%$ followed by Arkansas at $34.6 \%$ (Trust for America's Health and RWJF, 2014). All states are now above $20 \%$ in adult obesity (Trust for America's Health and RWJF, 2014). Because Tennessee is rated fourth in the nation and obesity is still increasing at a significant rate, it is necessary to know the perceptions of the nurses on role modeling health promotion and their health behaviors in order to maximize the potential for nurses to impact health behaviors in Tennessee.

In an effort to improve the health of Americans, the federal government issues guidelines on nutrition and physical activity. These guidelines for a healthy, well-balanced diet encourage consuming more fruits, vegetables and whole grains, fat-free or low fat dairy products, and lean meats, poultry and fish. In addition, foods lower in salt, saturated fats, cholesterol, and sugars are recommended while processed foods should be avoided (health.gov, 2014). Current physical activity guidelines state that adults age 18 to 64 should receive 150 minutes of moderateintensity aerobic physical activity in no less than 10-minutes intervals in addition to 
strengthening exercises twice per week (President's Council on Fitness, Sports \& Nutrition website, n.d.).

Fifty percent of adults drink alcohol on a regular basis and $14 \%$ on an infrequent basis (U.S. Department of Agriculture and U.S. Department of Health and Human Services, 2010). The CDC estimates costs of excessive alcohol consumption in 2006 at $\$ 223.5$ billion and 88,000 deaths related to alcohol consumption in 2006-2010 (CDC, 2014c). Although excessive alcohol use is linked to violence, disease and accidents, some research indicates that alcohol use in moderation offers some health benefits (CDC, 2014c). Excessive alcohol use (more than eight drinks a week for women and more than 15 drinks a week for men) is linked to liver disease, stroke and cardiovascular disease (CDC, 2011a; Patra et al., 2010; Poli et al., 2013). However, moderate alcohol use (one drink a day for women and two drinks a day for men) contributes to reduced risks of stroke, cardiovascular disease, and obesity (CDC, 2011a; Patra et al., 2010; Poli et al., 2013). Furthermore, some research indicates that abstaining from alcohol increases the risk of hypertension, metabolic syndrome, and obesity (Poli et al., 2013). In a longitudinal study of over 19,000 women, Wang, Lee, Manson, Buring, and Sesso (2010) found a weight gain of $3.1 \mathrm{~kg}$ in women that abstained from alcohol compared to $1.3 \mathrm{~kg}$ weight gain in participants with moderate alcohol intake.

Even with education to stop smoking and determinants of a healthy lifestyle to improve guidelines for nutrition, physical activity and alcohol consumption, the health status of the nation continues to deteriorate. As mortality rates and healthcare costs continue to rise, behaviors must change in order to change the health of the nation. The nation needs healthcare professionals to set lived examples of health for their community and to role model the behaviors that they encourage as an impetus for personal change in the patients they touch. 


\section{Nurses as Role Models of Health}

Anecdotal literature describes nurses as role models of health and wellness stating that exhibiting healthy lifestyles is a reflection of personal values and reveals beliefs about health (Borchardt, 2000; Cipriano, 2013; Denehy, 2003; Popplewell, 2006). Nursing leaders encourage nurses to improve their own health behaviors in an effort to fight obesity and promote health. Empirical studies also show that nurses are expected to be role models. Blake and Harrison (2013) surveyed 540 student nurses with $75 \%$ in agreement that nurses should be role models of health behaviors. In addition, 69\% agreed that "nurses should practice what they preach" (Blake \& Harrison, 2013, p. 90). In a study of 308 nurses Beletsioti-Stika and Scriven, (2006) found that nurses agree that they should be role models of health for their patients. In a survey of 504 physicians and nurses, Chan and Wong (2000) found that $81 \%$ believed that nurses should act as advocates of health and lead in disease prevention.

\section{Perception}

The literature clearly displays an expectation of the nurse as a role model of health; however few studies examined the nurses' view of themselves as role models. In a qualitative study of 11 nurses participating in focus groups, Rush, Kee, and Rice (2005), revealed that these nurses perceived society's view of a role model of health behaviors as connected to the nurse's credibility; however, they did not believe that self-care was a requirement to care for others. In contrast, Hensel (2008) found the characteristic of nurses' self-concept was significantly related to their lifestyle; with a higher self-concept, the nurse professed better ability to engage in caring relationships with patients and promote health. Petch-Levine, Cureton, Canham, and Murray (2003) surveyed 388 school nurses finding a significant correlation between perceived health status and weight $(r=-.29, \mathrm{p}<.05)$. Overweight school nurses perceived themselves to have 
poor health status. Beliefs of personal efficacy are significant to personal change and construct the foundation for motivation and action (Bandura, 2004). Nurses' self-perception is an essential component in understanding their values and beliefs around health in order to advocate change in themselves and others.

\section{Current State of Health of Nurses}

Nutrition and physical activity of nurses were consistent with the data on the general population. A study of 540 nursing students reported $24 \%$ of the students surveyed as either overweight or obese, $47 \%$ were not physically active enough for health benefit, and $73 \%$ did not eat a healthy diet indicating poor lifestyle behaviors and poor role modelling for the community (Blake \& Harrison, 2013). A study of 6 regions across the United States in 2007 reported 54\% of the 760 nurses surveyed as overweight or obese (Miller, Alpert, \& Cross, 2008). In another study, Malik, Blake and Batt (2011) surveyed 325 nursing students and 551 registered nurses and found that $48 \%$ of the nurses had an average BMI of 24.76 and did not participate in physical activity for 30 minutes most days of the week. In addition, $64 \%$ did not consume recommended fruits and vegetables and $42.5 \%$ ate sugar and fat on a daily basis. In another study, Tucker, Harris, Pipe, and Stevens (2010) surveyed 2,927 nurses and reported average BMI of 26.72 (SD $=5.86$, median $=25.93)$. Fifty three percent of the sample was overweight and $23 \%$ obese (Tucker et al., 2010). Among the examples listed above and seven other studies that reported similar results related to the health status of nurses, BMI mean average ranged from 24 to 27.3; overweight nurses represented from 18.1 to $57 \%$ of the nursing population and 9 to $16.6 \%$ were classified as obese (Allison, 2005; Blake et al., 2011; Esposito \& Fitzpatrick, 2011; Melynk, Hrabe, \& Szalacha, 2013; Petch-Levine et al., 2003; Roux et al., 2013; Zitkus, 2011). 
Reports in the literature on smoking status of nurses are similar to the national average. Petch-Levine et al. (2003), report $26 \%$ of school nurses as former smokers with only four percent as current smokers. In a study of nursing students $(n=325)$ and registered nurses $(n=551)$ 18.9\% currently smoke (Malik et al., 2011). Sarna, Bialous, Nandy, and Yang (2012) report only $12.1 \%$ of participants $(\mathrm{n}=2,566)$ as current smokers. According to a report on the Nurses' Health Study ( $\mathrm{n}=50,112), 19 \%$ of deaths related to smoking in 1986-2004 (Baer et al., 2010). The status of nurses that smoke and mortality rates from smoking parallel to the national average.

Reports of alcohol use and results of health outcomes indicate similar results to the national average. A report on the Nurses' Health Study $(n=50,112)$, indicate a decrease in risk factors with moderate alcohol use with $44 \%$ of the nurses in the study consuming alcohol at a moderate level and $21 \%$ consuming above the level of moderation (Baer et al., 2010). Blake and Harrison (2013) report approximately $33 \%$ of nursing students $(n=540)$ consuming alcohol on a moderate basis while 40\% reported exceeding the recommendations. Blake and Harrison (2013) found no significant correlation between alcohol consumption and weight.

According to the literature, nurses are not unlike the general population. Nurses are expected to model healthy behaviors and teach the public how to manage their unhealthy behaviors; however, based on the literature, nurses are struggling with the same unhealthy behaviors and sharing the same outcomes as the public. Unhealthy practices of nurses may directly affect their behavior and effectiveness in regards to health promotion (Hicks et al., 2008). 


\section{Nurses and Health Promotion}

Review of the literature identifies that in order to be effective in promoting healthy behaviors, the nurse must first be a role model. Being a role model gains credibility in the public and increases the likelihood of change in the patient (Blake \& Chambers, 2011; Illingworth, 2006). Nurses are in a position to educate and model healthy behaviors; however, the literature indicates that nurses are struggling with promoting health because their own health behaviors are poor. Practicing healthy behaviors is found to affect whether the nurse teaches healthy behaviors to patients. For example, in a national sample of 760 nurses self-reported $54 \%$ overweight or obese and $93 \%$ of nurses agreed that intervention is needed with obesity; nevertheless, $76 \%$ do not discuss the topic of losing weight with overweight and obese patients (Miller, Alpert, \& Cross, 2008). In addition, Blake and Harrison (2013) surveyed 540 pre-registered nurses and reported $88 \%$ believed that patients would follow their advice only if they appeared to follow the advice they were giving while 55\% acknowledged difficulty in promotion of health behaviors when their own behaviors were inadequate. In a study of 1,074 nurses, Slater, McElwee, Flemming, and McKenna, (2006) reported that smokers underestimated the risks of smoking (p < 0.001), the benefits of smoking cessation $(\mathrm{p}<0.05)$ and were less likely to provide smoking education to their patients. This information was supported in six other studies (Beletsioti-Stika \& Scriven, 2006; Hensel, 2008; Movsisyan et al., 2012; Roux et al., 2013; Willaing, Jorgensen, \& Iversen, 2003; Willaing \& Ladelund, 2004).

Nurses are consistently known as the most trusted profession ("Nurses at top in trust," 2012). Because of the number of nurses and the frequent contact with the public, nurses are a critical component in the environment to influence the improvement of health and wellness (Borchardt, 2000; Montoya \& Kozeliski, 2014). Nursing faculty members also have a substantial 
influence on nursing students. Just as nursing faculty can role model exemplary care and professionalism, role modeling healthy behaviors will potentially encourage the students to be exemplars for clients in their own nursing career (Blake et al., 2011; Klunkin et al., 2011).

\section{Gaps in the Literature}

Although literature contains accounts that nurses who do not practice healthy behaviors do not promote healthy behaviors, very little is known about the nurses' perception of self as role models for health promotion in relation to their health practices. Knowledge of nurses' selfperception may provide needed information regarding their value of health and barriers to health promoting behaviors that impact personal health practices. Hensel (2008) surveyed 132 nurses and found that if the nurse perceived a healthy lifestyle, they were more likely to participate "in caring relationships with their patients, use nursing knowledge, share information with patients and colleagues, and direct the health care team" (p. 53 ). Knowing the values and perceptions of nurses will close a knowledge gap and impact strategies used to assist nurses to change their own unhealthy behaviors.

The findings of the literature suggest that more research is needed to identify barriers that prevent nurses from leading healthy lifestyles and serving as a role model of health (Blackwell, 2004). As many studies demonstrate that nurses do not lead healthy lifestyles, it is not known how their self-perception as a role model relates to their healthy lifestyle behaviors. Knowing the nurses' perception, values, and factors that prevent healthy behaviors would allow for development of interventions to improve the health of nurses (Beletsioti-Stika \& Scriven, 2006; Blackwell, 2004; Hensel, 2008; Slater et al., 2006). This could be accomplished through further validation of the SARMHEP and correlated to nurses' healthy lifestyle behaviors. This results of 
this study have the potential to provide key information that can be used to promote health among nurses and improve the potential for nurses to promote healthy behaviors in their patients. 


\section{CHAPTER 3}

\section{METHODS}

\section{Research Design}

This study used a quantitative correlational design to describe relationships between the variables specifically using a correlation matrix and multiple regression. There was no intervention or manipulation of the variables in the study. According to Huck (2012), correlational studies are used to find relationships between variables and investigate the extent of the relationship among the variables. A correlation coefficient within a matrix is a bivariate correlational technique used to compare quantitative raw scores to indicate significance in the relationship (Huck, 2012). Multiple regression explains the relationship between one or more independent variables and can accommodate covariates analysis (Huck, 2012). The data for this study were obtained through self-administered questionnaires completed by randomly selected participants from the population of professional nurses in the state of Tennessee.

\section{Sample and Setting}

In 2014 , there were a total of 88,859 nurses employed in the state of Tennessee (Tennessee Board of Nursing, [TBN], 2014). This population was large enough to provide the data to answer the research questions proposed. The researcher requested a database from the TBN for professional Registered Nurses. Based on the general rule of 50 participants for each variable, the 13 variables in this study required a minimum sample size of 650 to adequately represent the population (Thomas \& Nelson, 2001). Inclusion criteria are active Registered Nursing license in the state of Tennessee, and a valid email in the available database. Exclusion criteria are non-registered nurses, invalid email in the available database, inactive nursing 
license, and substantially incomplete questionnaires (questionnaires must be $80 \%$ complete). Data were collected through an anonymous, on-line questionnaire.

\section{Instrumentation}

\section{Self as Role Model for Health Promotion}

The purpose of the Self as Role Model for Health Promotion (SARMHEP) tool is to measure nurses' perception of role modeling and promoting health. The instrument originated with 98-items. This is the first instrument to measure nurses' self-perceptions as role models and promoting health. Through both deductive and inductive processes, conceptual dimensions emerged and were analyzed. Through exploratory factor analysis, five factors accounted for $44 \%$ of the variance to guide the development of the 57-item instrument (Rush, Kee, \& Rice, 2010). The SARMHEP is a 57-item survey instrument with scores ranging from 57 to 342 . The Likerttype scale was based on $1=$ strongly disagree, $2=$ moderately disagree, $3=$ slightly disagree, $4=$

slightly agree, $5=$ moderately agree, and $6=$ strongly agree. A low score $57-151$ indicates that the participants view themselves as having to be perfect and on a pedestal, with their behaviors and practices more extrinsically motivated; attention is on behavioral compliance more than with the relationship of the client; less accepting of health behavior imperfections (Rush et al., 2010). A medium score 152-246 indicates that the participant self-perceives as a blend of ideal and humanistic role model; strive for ideal but acknowledge imperfections; balance behavioral compliance within context of caring partnerships with the client; personal health practices have elements of both extrinsic and intrinsic motivation. A high score 247-342 indicates that the participant self-perceives as humanistic role model; use themselves as caring partners in relationships with clients; acknowledges imperfections that can be used to help clients; and their health practices are intrinsically motivated for their own personal well-being (Rush, et al., 2010). 
This instrument is classified as specific because it directly applies to nurses and their perception of themselves and their practice. Kane and Radosevich (2011) describe condition specific measures as two types: clinical and experiential. This instrument falls under the experiential because it is "fine tuned to the specifics" of this population (Kane \& Radosevich, 2011, p. 133). A panel of nurses developed, analyzed, and evaluated the instrument through factor analysis in the theoretical phase, the operationalization phase, and the psychometric testing phase (Rush et al., 2010). The instrument was examined for validity and reliability testing with nurses. It could be argued that this instrument would relate to all healthcare professionals; however, no validity and reliability testing with participants other than nurses has been conducted at this time.

The authors assessed the reliability and validity of the instrument in three phases. In phase one, the development of the SARMHEP, the content was supported in the deductive process and review of the literature. Theoretical and empirical concepts of health promotions were identified to assist in formulation of content. Inductively, qualitative measures such as focus groups and personal interviews provided data to support emerging conceptual dimensions and sub-dimensions (Rush et al., 2010).

In phase two, the first step in testing the SARMHEP questionnaire was to investigate the content validity and internal consistency of the tool as determined by an expert review panel. The content validity index (CVI) for each item was quantified based on the panel review. Ten items scored less than .50 CVI. Five items were deleted, five items required clarification and additional questions were added (Rush et al., 2010). The CVI for the total scale of 95-items was calculated at .90 (Rush et al., 2010). 
In phase three, factor analysis was used to determine construct validity. The instrument was tested on a sample size of 115 participants with a variety of nursing backgrounds. A coefficient alpha of .87 was calculated (Rush et al., 2010). With individual item examination for its contribution to the total score, 75 -items were identified as having positive alpha correlations. Items with low correlations were removed to increase the reliability of the instrument. The standardized coefficient alpha for the remaining 75-items was .91 (Rush et al., 2010). Reliability was determined through psychometric evaluation. With further factor analysis, five factors were identified as salient and resulted in reducing the instrument to 57 -items. This simple five-factor structure included items that had loadings equal to or greater than .40 (Rush et al., 2010). The five factors accounted for $44 \%$ of the variance in the data (Rush et al., 2010). The coefficient alpha for the final 57-item scale was .90 (Rush et al., 2010).

Limitations to the reliability and validity of the instrument include limited amount of data collected using the instrument. The only data available are the data used in developing and critiquing the instrument through the initial process. There is no published use of the instrument since development in 2010 .

The instrument is multidimensional. Through factor extraction and factor rotation, five factors were identified. The covariance of $44 \%$ supports the multidimensional pattern. The five domains include: "use of professional self as caring partner in health promotion; identification of self with idealized image of role model; use of imperfect self in health promotion; valuing self in health promotion; and identification of self as health promoter (Rush et al., 2010). The SARMHEP is found in Appendix (B). Permission to use the questionnaire was obtained from Dr. Rush. 


\section{Demographic Variables}

Demographic information was collected through questions intended to categorize individuals by a number of factors. The participants were asked to provide general information, such as age, gender, ethnic group, education, height and weight. Participants were asked about area of residence including east, middle or west Tennessee and if they live in a rural, urban or suburban area. They were also asked to provide information specific to their nursing career, including years of experience, specific degree, place of employment, approximate income. Furthermore, the demographics assessed respondent behaviors based on the definition of a healthy lifestyle. Respondents were asked about smoking status, alcohol use, nutrition and physical activity, based on the guidelines described previously. The demographic questionnaire is found in Appendix (A).

\section{Data Collection and Procedures}

After dissertation committee and Institutional Review Board (IRB) approval, the TBN was contacted for permission to use the state nursing database for the study. This database provided enough contacts to recruit participants and present a representative sample of the nursing population in the state of Tennessee.

To randomly select possible participants for the study, a random number generator function was used in Microsoft Excel to assign a number to each person in the database. The listing was then ranked in numerical order. On average, $10 \%$ of recipients respond to an online survey of more than 20 questions (Deutskens, Ruyter, Wetzels, \& Oosterveld, 2004). Therefore, to meet the needs of the minimum sample needed, allow for inaccurate emails, and incomplete surveys, the first 10,000 numbers were emailed a letter that introduced the study and a link to follow if they chose to participate in the study. The email is found in Appendix C. The 
SARMHEP and demographics surveys were entered into an online database, Checkbox ${ }^{\circledR}$, to which the participant will connect after reading the email and deciding to participate. Two weeks after the initial email, a follow up email was sent to remind the individuals of the opportunity to participate in the research study. Due to a low response rate, four weeks after the initial email, a second randomly selected group from the database was emailed to participate in the study, following the same sampling procedure. A reminder email was sent to the second group two weeks after the initial email. A sufficient number of responses were received after the 8-weeks and the data were downloaded to Statistical Package for the Social Sciences (SPSS) Version 22.0 and the findings analyzed.

Upon completion and submission of the questionnaires, the participants had an opportunity to follow a separate link to enter their names into an incentive drawing. The questionnaire was not linked to the incentive drawing information, thus maintaining anonymity. A separate survey was available for the respondents to enter their information. Fifty dollar gift cards were given to two winning participants. Each participant entered in the incentive drawing was assigned a number and a random number generator chose two numbers as winners. Once the drawing was completed and gift cards were distributed to the winners, this information was deleted.

\section{Protection of Human Subjects}

After approval from IRB, randomly selected participants received an email to participate in the study. The email assured the participant of confidentiality and reporting of only group data. The name or email was not linked to the participant's responses. No names, emails, or identifying information was listed in Checkbox ${ }^{\circledR}$. Data were downloaded from Checkbox ${ }^{\circledR}$ in to 
SPSS ${ }^{\circledR}$ and analyzed for accuracy. The information was stored on a flash drive in a locked drawer in the researcher's office. There were no anticipated participant risks with this study.

\section{Data Analysis}

The SPSS 22.0 for Windows was used to perform all data analyses. Data were analyzed using descriptive statistics, a correlation matrix and multiple regression. Frequencies, percentages, means, and standard deviations summarized demographic characteristics of participants. Multiple regression determined significant predictors to the criterion, the extent of each predictor's contribution to the criterion, and the direction of the contribution to the criterion (Huck, 2012).

Research question 1) Is there a relationship between perception of self as a role model of healthy behaviors as measured by the Self as a Role Model of Health Promotion (SARMHEP) scores and personal health behaviors reported in the demographics? This question was analyzed with a correlation matrix. A correlation matrix summarized the measured bivariate relationships among the variables (Huck, 2012). Each behavior, smoking, alcohol use, healthy diet, and physical activity, were correlated to the SARMHEP score in the matrix using the separate bivariate $r$ s.

Research question 2) To what extent do practice settings, educational preparation, years

of practice experience, race and ethnicity, gender, age, region and type of community contribute to perception of self as a role model of healthy behaviors as measured by SARMHEP scores? This question was analyzed using multiple regression. Multiple regression determined significant predictors to the criterion (SARMHEP scores), the extent of each predictor's contribution to the criterion, and the direction of the contribution to the criterion (Huck, 2012). 
Research question 3) To what extent do practice settings, educational preparation, years of practice experience, race and ethnicity, gender, age, region and type of community contribute to smoking as reported in the demographics? Research question 4) To what extent do practice settings, educational preparation, years of practice experience, race and ethnicity, gender, age, region and type of community contribute to alcohol use as reported in the demographics? Research question 5) To what extent do practice settings, educational preparation, years of practice experience, race and ethnicity, gender, age, region and type of community contribute to healthy diet as reported in the demographics? Research question 6) To what extent do practice settings, educational preparation, years of practice experience, race and ethnicity, gender, age, region and type of community contribute to physical activity as reported in the demographics? Research questions three, four, five, and six was analyzed using multiple regression. The criterion in each question is the measured behavior (smoking, alcohol use, healthy diet, and physical activity). Multiple regression measured significant predictors to the criterion, the degree of each predictor's influence to the criterion, and the direction of the relationship to the criterion (Huck, 2012).

Research question 7) To what extent do Tennessee nurses report personal health behaviors? This question was analyzed using descriptive statistics. Descriptive statistics summarize univariate data (Huck, 2012). Frequencies and percentages describe each behavior reported by the participants.

\section{Summary}

Nurses are seen by others as health experts. Nurses' personal health decisions are portrayed to others through observation and education. Nurses must perceive themselves as leaders in promoting health to the nation before they can motivate others to create change. This 
study has the potential to provide key information about health promotion among nurses.

Ultimately, the knowledge gained will have the potential to improve nurses' ability to serve as role models and motivate others toward healthy behaviors that will reduce morbidity and mortality, and strategically reduce health care costs. 


\section{CHAPTER 4}

\section{RESULTS}

This study explore the nurses' perception of self as a role model of health and personal healthy lifestyle behaviors and focuses on four specific behaviors that lead to a healthy lifestyle: limit alcohol, avoid tobacco, improve nutrition, and engage in physical activity. The purpose of this study was to determine the relationship between nurses' health practices and their perceptions of self as role models for health promotion. The population for this study was Tennessee registered nurses. The nurses were randomized from the TBN database by applying a random number generator and then ranked into numerical order. A total of 20,000 nurses were sent an email to recruit participants. The participants were asked to complete a demographic survey (Appendix A) and the SARMHEP self-perception survey (Appendix B). Data were collected through an anonymous, on-line questionnaire using Checkbox ${ }^{\circledR}$. The data were then uploaded to SPSS 22.0 for analysis.

\section{Description of Participants}

A total of 1,428 participants responded to the email by following the link to the survey. Questionnaires that were less than $80 \%$ complete were excluded from the sample. The final sample consisted of 804 registered nurses in the state of Tennessee. There were $716(89 \%)$ females and $86(10.7 \%)$ males. The percent of male nurses in the sample was comparable to male nurses in the national nursing population at 9\% (Health Resources and Services Administration [HRSA], 2013). Two participants did not indicate their gender. The mean age of the participants was 48 years old. The majority $(91 \%)$ of the respondents were Caucasian ranging from one to 60 years of nursing experience. The majority (43.9\%) of respondents work in an inpatient/acute care 
facility and hold a BSN degree (51.4\%). A more detailed description of the participant demographics is presented in Table 1.

Table 1 Participant Demographics

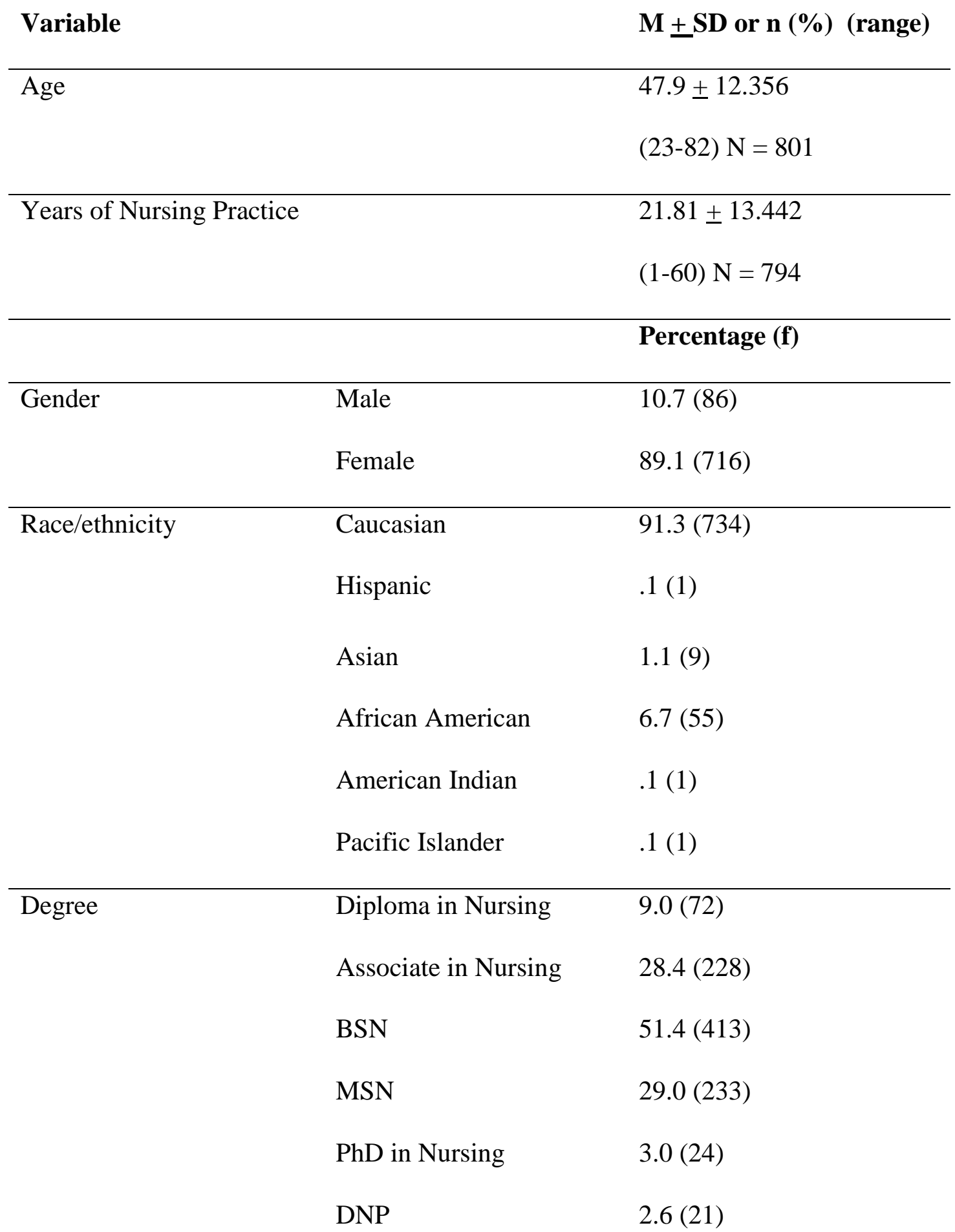


Table 1 (continued)

\begin{tabular}{|c|c|c|}
\hline Variable & & Percentage (f) \\
\hline \multirow[t]{11}{*}{ Area of Employment } & Inpatient/Acute Care & $43.9(353)$ \\
\hline & Ambulatory & $13.8(111)$ \\
\hline & College/Academia & $10.6(85)$ \\
\hline & Community & $9.7(78)$ \\
\hline & Private Practice & $8.5(68)$ \\
\hline & Industry & $4.5(36)$ \\
\hline & Long Term Care & $4.2(34)$ \\
\hline & Home Health/Hospice & $4.1(33)$ \\
\hline & School Nursing & $3.5(28)$ \\
\hline & Retired & $1.9(15)$ \\
\hline & Unemployed & $1.5(12)$ \\
\hline \multirow[t]{3}{*}{ Region of Tennessee } & East & $38.2(307)$ \\
\hline & Middle & $41.2(331)$ \\
\hline & West & $20.3(163)$ \\
\hline \multirow[t]{3}{*}{ Type of Community } & Rural & $34.6(278)$ \\
\hline & Urban & $21.8(175)$ \\
\hline & Suburban & $43.8(352)$ \\
\hline
\end{tabular}

\section{SARMHEP Scores}

The SARMHEP scores ranges from 57 to 342 . The Likert-type scale was based on $1=$ strongly disagree, $2=$ moderately disagree, $3=$ slightly disagree, $4=$ slightly agree, $5=$ 
moderately agree, and $6=$ strongly agree. The scores are categorized into low (57-151), medium (152-246) and high (247-342). Only one participant scored in the low category (.1\%), 449 in the medium category $(55.7 \%)$ and 354 in the high category $(44.2 \%)$.

\section{Data Analysis}

Research question 1) Is there a relationship between perception of self as a role model of healthy behaviors as measured by the Self as a Role Model of Health Promotion (SARMHEP) scores and personal health behaviors reported in the demographics?

The Cronbach's alpha reliability coefficient on the overall 57-item questionnaire was .82. This question was analyzed with a Pearson $r$ correlation matrix. Each behavior (smoking, alcohol use, healthy diet, and physical activity) were correlated to the SARMHEP score in the matrix using the separate bivariate $r$ s. Correlations between SARMHEP total scores and smoking yielded results of $r=.02, \mathrm{p}>.05 ;$ SARMHEP total scores and alcohol, $r=.01, \mathrm{p}>.05$. There was no significant correlation between smoking or alcohol use and the SARMHEP scores. Correlations between SARMHEP total scores and healthy diet, $r=.15, \mathrm{p}<.01$; SARMHEP total scores and physical activity, $r=.11, \mathrm{p}<.01$. There was a significant weak correlation between following a healthy diet or physical activity and the SARMHEP scores. Sixty-three percent of the participants described themselves as a good or very good role model of health.

A Pearson $r$ correlation matrix was used to analyze the subscales of the SARMHEP. Selfefficacy was analyzed with the following subscales: "use of professional self", "use of imperfect self", "valuing self" and "self as a health promoter". A Cronbach's alpha reliability coefficient for "use of professional self" and "valuing self" were .933 and .723. Correlations between "use of the professional self" and health behaviors yielded significant results in a healthy diet and exercise $(r=.096, \mathrm{p}<.01 ; r=.098, \mathrm{p}<.05)$. Correlations between the subscale of "valuing self" 
and health behaviors yielded significant positive results in a healthy diet and exercise and a negative correlation with smoking $(r=.532, \mathrm{p}<.01, r=.333, \mathrm{p}<.01, r=-.090, \mathrm{p}<.05)$. Outcome expectancy was analyzed with the subscale of "identification of self with the idealized". There was no significant correlations in the subscale of "identification of self with the idealized" and health behaviors.

Research question 2) To what extent do practice settings, educational preparation, years of practice experience, race and ethnicity, gender, age, region and type of community contribute to perception of self as a role model of healthy behaviors as measured by SARMHEP scores?

This question was analyzed using multiple regression backward method to determine significant predictors with .05 tolerance. The ANOVA for the overall regression is trustworthy $(\mathrm{F}=9.933, \mathrm{p} .<.01)$ in the best model. The Beta coefficients were: SARMHEP $=-5.603$ (acute care $)-5.100$ (ambulatory care $)+.06($ age $)+233.997$. A forward method of regression was conducted on the significant predictors indicated by the backward procedure to look for $\mathrm{R}^{2}$ change. Acute care employment negatively accounted for about $2 \%$ of the variance in the SARMHEP scores $(\beta=-.137)$. Adding the age variable significantly increased the variance to $3 \%(\beta=.107 ; \mathrm{p}<.01)$. Ambulatory care employment also significantly and negatively accounted for more variance in the SARMHEP score $(\beta=-.081$, almost $4 \%, \mathrm{p}<.05)$. These contributions appear significant however, more than $95 \%$ of variance in SARMHEP scores is still unaccounted.

Research question 3) To what extent do practice settings, educational preparation, years of practice experience, race and ethnicity, gender, age, region and type of community contribute to smoking as reported in the demographics? This question was analyzed using multiple regression backward method to determine significant predictors with .05 tolerance. The ANOVA 
for the overall regression is trustworthy $(\mathrm{F}=11.754, \mathrm{p} .<.01)$. In the best model only two predictors significantly contributed to smoking: long-term care as area of employment and home health/ hospice as area of employment $(\beta=0.97, \mathrm{p}<.01 ; \beta=.143, \mathrm{p}<.01)$. The two predictors account for only $3 \%$ of the variance, therefore $97 \%$ of the variance is unaccounted.

Research question 4) To what extent do practice settings, educational preparation, years of practice experience, race and ethnicity, gender, age, region and type of community contribute to alcohol use as reported in the demographics? This question was analyzed using multiple regression backward method to determine significant predictors with .05 tolerance. The ANOVA for the overall regression is trustworthy $(\mathrm{F}=7.32, \mathrm{p} .<.01)$. The best model revealed two predictor variable that contributed significantly to alcohol use: ethnicity and academia as the area of employment $(\beta=.087, \mathrm{p}<.05 ; \beta=.105, \mathrm{p}<.01)$. The two predictors account for only $2 \%$ of the variance, therefore $98 \%$ of the variance is unaccounted.

Research question 5) To what extent do practice settings, educational preparation, years of practice experience, race and ethnicity, gender, age, region and type of community contribute to healthy diet as reported in the demographics? This question was analyzed using multiple regression backward method to determine significant predictors with .05 tolerance. The ANOVA for the overall regression is trustworthy $(\mathrm{F}=12.931, \mathrm{p} .<.01)$. The best model revealed five predictor variables that contributed significantly to following a healthy diet. An associate degree in nursing and long-term care as the area of employment significantly and negatively contributed to following a healthy diet $(\beta=-.093, p<.01 ; \beta=0.85, p<.05)$. Nurses that had a master's degree, a higher number of years as being a nurse and working as a school nurse significantly contributed to following a healthy diet $(\beta=.097, \mathrm{p}<.01 ; \beta=.187, \mathrm{p}<.01 ; \beta=.079, \mathrm{p}<.05)$. 
The five predictors account for only $8 \%$ of the variance, therefore $92 \%$ of the variance is unaccounted.

Research question 6) To what extent do practice settings, educational preparation, years of practice experience, race and ethnicity, gender, age, region and type of community contribute to physical activity as reported in the demographics? This question was analyzed using multiple regression backward method to determine significant predictors with .05 tolerance. The ANOVA for the overall regression is trustworthy $(\mathrm{F}=6.094, \mathrm{p} .<.01)$. The best model revealed three variables that significantly contributed to physical activity: nurses that have a master's degree and the number of years of nursing positively contribute to physical activity $(\beta=.128, p<.01 ; \beta$ $=.083, \mathrm{p}<.05)$, working in the area of academia negatively contributes to physical activity $(\beta=$ $-.073, \mathrm{p}<.05)$. The three predictors account for only $2 \%$ of the variance, therefore $98 \%$ of the variance is unaccounted.

Research question 7) To what extent do Tennessee nurses report personal health behaviors? This question was analyzed using descriptive statistics. Frequencies and percentages describe each behavior reported by the participants. Four percent of the respondents report currently smoking and $24.9 \%$ report alcohol use. The majority report eating a healthy diet between 50 to $70 \%$ of the time (46.6\%). Almost 70\% of respondents report exercising less than the recommended 150 minutes a week. Sixty four percent were overweight or obese based on self-reported height and weight. A more detailed description of the participants' reported health behaviors is presented in Table 2 . 
Table 2 Healthy Behaviors and BMI

\begin{tabular}{|c|c|c|c|}
\hline $\begin{array}{l}\text { Health } \\
\text { Behavior }\end{array}$ & & & Percentage (f) \\
\hline \multicolumn{4}{|l|}{ Smoking } \\
\hline & \multicolumn{2}{|l|}{ Non-smoking } & $95.0 \%(764)$ \\
\hline & \multicolumn{2}{|l|}{ Smoking } & $4.1 \%(33)$ \\
\hline & \multicolumn{2}{|l|}{ Not recorded } & $0.9 \%(7)$ \\
\hline & \multicolumn{2}{|l|}{ Totals } & $100.0 \%(804)$ \\
\hline \multicolumn{4}{|l|}{ Alcohol Use } \\
\hline & \multicolumn{2}{|l|}{ Yes } & $24.9 \%(200)$ \\
\hline & \multicolumn{2}{|l|}{ No } & $72.1 \%(580)$ \\
\hline & \multicolumn{2}{|l|}{ Not recorded } & $3.0 \%(24)$ \\
\hline & \multicolumn{2}{|l|}{ Totals } & $100.0 \%(804)$ \\
\hline \multicolumn{4}{|l|}{ Healthy Diet } \\
\hline & \multicolumn{2}{|l|}{ Under $50 \%$} & $16.5 \%(132)$ \\
\hline & \multicolumn{2}{|l|}{$50 \%$ to $79 \%$} & $46.6 \%(375)$ \\
\hline & \multicolumn{2}{|l|}{$80 \%$ to $100 \%$} & $36.2 \%(291)$ \\
\hline & \multicolumn{2}{|l|}{ Not recorded } & $0.7 \%(6)$ \\
\hline & \multicolumn{2}{|l|}{ Totals } & $100.0 \%(804)$ \\
\hline \multicolumn{4}{|l|}{ Exercise } \\
\hline & \multicolumn{2}{|l|}{$<150$ minutes } & $70.3 \%(560)$ \\
\hline & \multicolumn{2}{|l|}{150 minutes or more } & $29 \%(237)$ \\
\hline & \multicolumn{2}{|l|}{ Not recorded } & $0.7 \%(6)$ \\
\hline & \multicolumn{2}{|l|}{ Totals } & $100.0 \%(804)$ \\
\hline \multicolumn{4}{|l|}{ BMI } \\
\hline & Underweight & Below 18.5 & $1.1 \%(9)$ \\
\hline & Normal/Healthy Weight & 18.5 to 24.9 & $32.3 \%(260)$ \\
\hline & Overweight & 25.0 to 29.9 & $34.0 \%(273)$ \\
\hline & Obese & 30.0 and & \\
\hline & Obese & Above & $30.0 \%(241)$ \\
\hline & Not recorded & & $2.6 \%(21)$ \\
\hline & Totals & & $100.0 \%(804)$ \\
\hline
\end{tabular}

\section{Summary}

This study provided information that described how Tennessee nurses perceived themselves as role models of health and describe their health behaviors. This is important because nurses are the largest and most trusted health profession and they greatly influence the populations they serve. In this study, $4 \%$ report smoking, $24.9 \%$ drink alcohol, $34 \%$ are 
overweight and $30 \%$ obese. Approximately $70 \%$ do not meet the weekly physical activity recommendations of 150 minutes and $16.5 \%$ follow guidelines for a healthy diet less than $50 \%$ of the time. There was no significant correlation between smoking or alcohol use and the SARMHEP scores. There was a significant correlation between following a healthy diet or physical activity and the SARMHEP scores. Based on the regression analysis, working in an acute care or ambulatory setting negatively affected the SARMHEP, as opposed to age and gender having a positive effect on the SARMHEP score. However, a significant relationship was noted between smoking and working in a long-term care facility or home health. Also, there was a significant relationship between alcohol use and working in the academic setting. While having an associate degree in nursing and working in a long-term facility significantly and negatively correlated to following a healthy diet, having a master's degree, working as a school nurse, and having more years as a nurse positively contributed to a healthier diet. There was a significant positive relationship between having a master's degree, more years of nursing experience and physical activity. However, there was a negative relationship between physical activity and working in academia. 


\section{CHAPTER 5}

\section{DISCUSSION, IMPLICATIONS AND RECOMMENDATIONS}

This study aimed to close the gap in knowledge of nurses' self-perception of being a role model of health and the personal health behaviors of a sample of nurses in Tennessee who were primarily female, Caucasian, mean age of 48 and a majority with a baccalaureate degree. The purpose of this study was to determine the relationship between the nurses' perceptions of self as role models for health promotion and their personal health practices. The study focused on four specific health behaviors (limit alcohol, avoid tobacco, improve nutrition, and engage in physical activity). This chapter presents the discussion of the findings, implications for practice, recommendations for future research and limitations of the study.

\section{Discussion}

A major finding indicates that there was a weak correlation between the participants overall perception of self as a role model and following a healthy diet and physical activity. The majority of the participants scored in the medium category on the SARMHEP scale indicating a self-perception of balance between the ideal and humanistic role model. The medium scale describes the participant as both intrinsically and extrinsically motivated by factors that affect their personal health behaviors. While they strive for the ideal behaviors, they acknowledge imperfections and achieve a balance. In the medium scale, the nurse also realizes a balance of the behavioral compliance within the caring relationship with the client (Rush et al., 2010). A large number of the participants also scored in the high category of the scale indicating that their selfperception of the role model is humanistic. The high score describes the participant as intrinsically motivated by factors that affect their own personal health behaviors. They may use their own imperfections as examples to motivate clients (Rush et al., 2010). Only one participant 
scored in the low category indicating their self-perception as an ideal role model. The low score describes the participant as having to be perfect, extrinsically motivated and less accepting of imperfect health behaviors in themselves and others (Rush et al., 2010).

The analysis of the subscales of the SARMHEP yielded significant positive correlations between "use of the professional self" and "valuing self" with diet and exercise. There was a negative correlation between "valuing self' with smoking. These findings indicate that a person's self-efficacy result in decisions of personal health behaviors. With a higher score in these subscales, the participant eats better, exercises more and is less likely to smoke. According to Bandura (2004) self-efficacy shapes the expectancy outcomes. A major finding indicated although the sample of participants reported overall medium to high scores on the SARMHEP instrument, the subscales indicate medium to high sense of self-efficacy correlated to health behaviors. However, there was no correlation between the outcome expectancies and the health behaviors. This inconsistency may explain the self-reported data of poor diet and exercise behaviors. In this study, nurses perceived themselves as role models and either have a balance of the ideal and humanistic role model or they are more humanistic, however they are not performing personal health behaviors. Sixty-three percent of the participants described themselves as a good or very good role model of health. These findings are consistent with a study that revealed that these nurses perceived society's view of a role model of health behaviors as connected to the nurse's credibility; however, they did not believe that self-care was a requirement to care for others (Rush et al., 2005).

Based on these findings, it seems that nurses have a self-perception that they are good role models. They either have a balance between the ideal and humanistic role model or their approach is more humanistic. Nurses do not strive to be the ideal role model for health 
promotion. They use their imperfections to motivate clients and maintain a caring relationship even as clients are noncompliant.

A second important finding was that although the participants reported overall good scores on the SARMHEP, $64 \%$ of the sample was either overweight or obese based on a selfreport of height and weight. These findings were consistent with several studies reporting overweight and obesity ranging from 27 to $74 \%$ (Blake \& Harrison, 2013; Esposito \& Fitzpatrick, 2011; Roux et al., 2013). The self-report results of following a healthy diet are greater than the general population, however, not performing physical activity was much greater than the general population at almost 70\% (CDC, 2009; CDC, 2014d). See Table 3 for a comparison of health behaviors of the national population and the results of this study. In this study only $4 \%$ reported smoking and $24.9 \%$ drinking alcohol. This report is much lower than the national data. This may be explained by national campaigns to educate the public about the harms of smoking and drinking alcohol that resulted in a steady decline in use in the nursing population. These findings are consistent with previous reports in smoking habits that indicate a decline in smoking among registered nurses in 2003 from 11\% to 7\% in 2011 (Sarna et al., 2014). Although there are now national campaigns about healthy eating and exercising in an effort to decrease the obesity epidemic, obesity rates are still on the rise. 
Table 3 Tennessee Nurses and National Data Comparison

\begin{tabular}{lll} 
& National Data & Tennessee Nurses \\
\hline Smoking & $18 \%$ & $4 \%$ \\
\hline Alcohol Use & $50 \%$ & $24.9 \%$ \\
\hline Follow a Healthy Diet & $14 \%$ & $36.2 \%$ \\
\hline Physical activity (less than 150 & $<50 \%$ & $29 \%$ \\
minutes weekly) & & \\
\hline BMI & $33.9 \%$ overweight & $34 \%$ Overweight \\
& $35.1 \%$ obese & $30 \%$ obese \\
&
\end{tabular}

Note. National Data is based on the general U.S. population

Interestingly, working in the areas of acute care or ambulatory negatively affected the SARMHEP scores, as opposed to age and gender having a positive effect on the SARMHEP. The findings in this study may indicate acute care and ambulatory care as stressful fast paced environments where nurses may have less option to choose healthier foods due to time and location. These finding were supported by Tucker et al. (2010) reported that work environments were rated higher with jobs that were perceived as having less stress and fewer snacks or fast foods. Age had a positive effect on the SARMHEP scores which may indicate that as nurses' age, they have an increase in valuing their own health. Because the participants were majority female, the effect of gender may need further research to validate the finding. A significant relationship was noted between smoking and working in a long-term facility or home health. These areas of employment are not as strictly regulated as hospitals, universities or schools and allow smoking on the premises and therefore may explain the findings (TN Department of Health, n.d.). 
Having an associate degree in nursing and working in a long-term facility significantly and negatively correlated to following a healthy diet whereas, having a master's degree, working as a school nurse, and having more years as a nurse positively contributed to a healthier diet. There was also a significant positive relationship between having a master's degree, having more years of nursing experience, and physical activity. Based on these findings, it seems that being a nurse for a longer amount of time and having a master's degree more positively influenced the health behaviors of the nurse. Considering the findings of working in a long term facility negatively affects a healthy diet while working as a school nurse positively affects a healthy diet is explained by the focus to improve the health of children. There are many campaigns and policies that focus on children in the school to improve their diet and increase exercise including the Hungry Free Healthy Kids Act (2010). This bill may explain the influence on diet and exercise of the school nurse whereas there has been no campaign to focus on the diet of long term care clients. Current literature does not differentiate in the areas of work, level of education and personal health behaviors.

There was a significant relationship between alcohol use and working in the academic setting, however, no current literature supported or contradicted this finding. There was also a significant negative relationship between working in academia and physical activity. These findings may be explained by the faculty shortage and the workload of nursing faculty. A study conducted in 2006 by NLN and the Carnegie Foundation surveyed 8,498 nurses in education. Respondents reported working an average of 56-hours a week while engaging in professional activities outside of their work week and 9\% had more than one paid job (Kaufman, 2007). Forty six percent of the respondents time was spent teaching as it was identified as the most "timeintensive" task performed by the nurse educator (Kaufman, 2007). In addition, almost another 
$30 \%$ of was time spent in clinical or directly working with students (Kaufman, 2007). This left $25 \%$ percent of their time to divide between clinical practice, department and university service, research and other duties that may be assigned (Kaufman, 2007). As faculty are promoted and tenured based on their ability to conduct research and publish, their free time to participate in their own healthy behaviors become very limited with this workload. This environment does not role model healthy behaviors to nursing students, nor does it portray an environment to entice nursing students to consider academia as an option in an effort to decrease the nursing faculty shortage.

\section{Implications for Practice}

The findings of this study indicate that nurses do not believe that their own personal health behaviors affect their professional practices. However, with a weak correlation between the participants overall SARMHEP and following a healthy diet and physical activity, and the moderate positive correlations between "use of the professional self" and "valuing self" subscales with diet and exercise, this may be the beginning of nurses changing their own personal practices to role model best practices to their clients as they have with smoking. Based on the literature, being a role model gains credibility in the public and increases the likelihood of motivating change in the population. (Blake \& Chambers, 2011; Illingworth, 2006). However, nurses are not currently meeting the current health standards related to exercise and physical activity. Therefore, nurses must begin to evaluate their own motivation and work environment to promote care in themselves as well as others.

Based on the findings of participants, having more years of nursing experience contribute to a healthy diet and exercise, the question arises as to what education is given to new nurses or nursing students about personal health behaviors related to role modeling. This study indicates 
that nurses in academia are more likely to use alcohol and less likely to exercise. These finding may be used for nurse educators to appraise their own motivation for personal health behaviors and consider their influence on nursing students. Nurse educator's role model best practices in the clinical setting for their students, but do they role model best health behaviors? The workload of the nurse educator should also be examined to determine an acceptable workload that includes an environment that promotes health in the faculty and in the students that they teach.

\section{Study Limitations}

There are some limitations of this study. First, the data collection for the study consists of self-reported data which includes a risk of over or under reporting behavior by the participant. Second, this is the first time use of instrument after development, therefore further validation of the tool may be needed. And finally, the questions to measure personal lifestyle behaviors were specifically developed for this study, but based on current literature and expert thinking on appropriate behaviors to promote health. The items included are consistent with the accepted guidelines.

\section{Future Research}

There was a low amount of variances accounted for in the data collected, therefore further assessment of the unaccounted variance is necessary. For future research, it is important to continue the validation of the SARMHEP instrument. Further psychometric analysis may assist in refining the instrument and further defining the subscales and measure the accuracy of the response. Replication of the study with the inclusion of a qualitative piece would allow for clarification of findings. Future studies are needed to explore the effect of nurses' personal health behaviors on client outcomes. Since this study identified that previous literature does not 
differentiate in the areas of work, level of education and personal health behaviors, further studies to explore work environments are warranted. Also, what influence do faculty as role models have on the effect of student perception of themselves as a role model? The effect of faculty workload on personal health behaviors would also benefit knowledge toward health promotion. In addition, identification of barriers to participation in healthy behaviors in each work setting may lead to interventions that would promote positive behaviors. Another area of research might include the client's perception of the nurse as a role model of health.

\section{Conclusion}

Nurses are the nation's largest group of healthcare professionals and are uniquely positioned to serve as effective role models of healthy behaviors. As role models, nurses should personally value health and assist to shape society's value of health. Based on this study, nurses in Tennessee have succeeded to influence the society to decrease smoking. Although literature reports that nurses are unhealthy and do not practice what they preach, this study reveals correlations that this may be changing (Blake \& Harrison, 2013; Miller et al., 2008). If nurses are going to lead the nation in healthcare, nurses must role model personal health behaviors to their clients. According to Bandura's (1977) Social Learning Theory behaviors are learned by observing others; the values and beliefs of the role model are adopted by the learner. Nursing faculty role model best practices in the clinical setting, they also need to role model best personal health practices to students. Nurses influence those around them in both the personal and professional setting, therefore as nurses extend positive lifestyle practices into their professional domain, they will make positive influences on their clients. 


\section{REFERENCES}

Allison, S. (2005). Biographic and psychobehavioral influences on body mass index in a nursing sample. Western Journal of Nursing Research, 27(1), 7-20. http://dx.doi.org/10.1177/0193945904265404

American Association of Colleges of Nursing. (2008).

The essentials of baccalaureate education for professional nursing practice. Retrieved from http://www.aacn.nche.edu/education-resources/BaccEssentials08.pdf

American Nurses Association. (2014). Healthynurse. Retrieved October 2014, from http://www.nursingworld.org/MainMenuCategories/WorkplaceSafety/Healthy-Nurse

Baer, H. J., Glynn, R. J., Hu, F. B., Hankinson, S. E., Willett, W. C., Colditz, G. A., ... Rosner, B. (2010). Risk factors for mortality in the Nurses' Health Study: A competing risks analysis. American Journal of Epidemiol, 173(3), 319-329.

http://dx.doi.org/10.1093/aje/kwq368

Bandura, A. (1977). Social learning theory. Englewood Cliffs, NJ: Prentice-Hall, Inc.

Bandura, A. (1986). Social foundations of thought and action. Englewood Cliffs, NJ: PrenticeHall, Inc.

Bandura, A. (2001). Social cognitive theory: An agentic perspective. Annual Review of Psychology, 52, 1-26. http://dx.doi.org/10.1146/annurev.psych.52.1.1

Bandura, A. (2004). Health promotion by social cognitive means. Health Education \& Behavior, 31(2), 143-164. http://dx.doi.org/10.1177/1090198104263660

Beletsioti-Stika, P., \& Scriven, A. (2006). Smoking among Greek nurses and their readiness to quit. International Nursing Review, 53, 150-156. 
Blackwell, J. (2004, February). The health styles of nurse practitioners. Journal of the American Academy of Nurse Practitioners, 16(2), 81-87.

Blake, H., \& Chambers, D. (2011). Supporting nurse health champions: Developing a 'new generation' of health improvement facilitators. Health Education Journal, 71(2), 205210. http://dx.doi.org/10.1177/0017896910396767

Blake, H., \& Harrison, C. (2013). Health behaviors and attitudes towards being role models. British Journal of Nursing, 22(2), 86-94. http://dx.doi.org/10.12968/bjon.2013.22.2.86

Blake, H., Malik, S., Mo, P. K., \& Pisano, C. (2011, September). 'Do as I say, but not as I do': Are next generation nurses role models for health? Perspectives in Public Health, 131(5), 231-239. http://dx.doi.org/10.1177/1757913911402547

Boaz, M., Rychani, L., Barami, K., Houri, Z., Yosef, R., Siag, A., ... Leibovitz, E. (2013). Nurses and nutrition: A survey of knowledge and attitudes regarding nutrition assessment and care of hospitalized elderly patients. The Journal of Continuing Education in Nursing, 44(8), 357-364. http://dx.doi.org/10.3928/00220124-20130603-89

Borchardt, G. L. (2000, July-September). Said another way: Role models for health promotion: The challenge for nurses. Nursing Forum, 35(3), 29-32.

Buxton, C., \& Davies, A. (2013). Nutritional knowledge levels of nursing students in a tertiary institution: Lessons for curriculum planning. Nurse Education in Practice, 13(5), 355360. http://dx.doi.org/10.1016/j.nepr.2012.09.014

Casey, D. (2007). Nurses' perceptions, understanding and experiences of health promotion. Journal of Clinical Nursing, 16, 1039-1049. http://dx.doi.org/10.1111/j.13652702.2007.01640.x 
Centers for Disease Control. (2009). State indicator report on fruits and vegetables, 2009.

Retrieved from http://www.cdc.gov/nutrition/downloads/StateIndicatorReport2009.pdf

Centers for Disease Control. (2011a). Four specific health behaviors contribute to a longer life.

Retrieved March 2015, from http://www.cdc.gov/Features/LiveLonger/

Centers for Disease Control. (2011b). State preemption of local tobacco control policies

restricting smoking, advertising, and youth access --- United States, 2000--2010.

Retrieved March 2015, from

http://www.cdc.gov/mmwr/preview/mmwrhtml/mm6033a2.htm

Centers for Disease Control. (2014a). Healthy weight - It's not a diet, it's a lifestyle. Retrieved

October 2014, from

http://www.cdc.gov/healthyweight/assessing/bmi/adult_bmi/index.html?s_cid=tw_ob064

Centers for Disease Control. (2014b). Obesity and overweight. Retrieved October 2014, from http://www.cdc.gov/nchs/fastats/obesity-overweight.htm

Centers for Disease Control. (2014c). Alcohol and public health. Retrieved March 2015, from http://www.cdc.gov/alcohol/data-stats.htm

Centers for Disease Control. (2014d). Facts about physical activity. Retrieved March 2015, from http://www.cdc.gov/physicalactivity/data/facts.html

Centers for Disease Control. (2015a). Leading causes of death. Retrieved March 2015, from http://www.cdc.gov/nchs/fastats/leading-causes-of-death.htm

Centers for Disease Control. (2015b). Tobacco-related mortality. Retrieved October 2014, from http://www.cdc.gov/tobacco/data_statistics/fact_sheets/fast_facts/

Chan, F. Y., \& Wong, G. K. (2000). Health promotion in hospitals: The attitudes of health care professionals. The Hong Kong Nursing Journal, 36(2), 7-15. 
Church, T. S., Thomas, D. M., Tudor-Locke, C., Katzmarzyk, P. T., Earnest, C. P., Rodarte, R. Q., ... Bouchard, C. (2011). Trends over 5 decades in U.S. Occupation-related physical activity and their associations with obesity. http://dx.doi.org/doi:10.1371/journal.pone.0019657

Cipriano, P. F. (2013). The healthy nurse. American Nurse Today, 8(1), 6.

Cordain, L., Eaton, S. B., Sebastain, A., Mann, N., Lindeberg, S., Watkins, B. A., ... BrandMiller, J. (2005). Origins and evolution of the Western diet: Health implications for the 21st century. American Journal of Clinical Nutrition, 81, 341-354.

Cruess, S., Cruess, R., \& Steinert, Y. (2008). Role modelling--making the most of a powerful teaching strategy. British Medical Journal (International Edition), 336(7646), 718-721. http://dx.doi.org/doi:10.1136/bmj.39503.757847.BE

Davidson Films (Producer). (2003). Bandura's Social Cognitive Theory [VHS]. Available from Davidson Films.

Denehy, J. (2003, October). School Nurses: Role models for healthy lifestyles? The Journal of School Nursing, 19(5), 249-250.

Deutskens, E., Ruyter, K. D., Wetzels, M., \& Oosterveld, P. (2004). Response rate and response quality of internet-based surveys: An experimental study. Marketing Letters, 15(1), 21 36.

Dworetzky, B. A., Bromfield, E. B., Townsend, M. K., \& Kang, J. H. (2010). A prospective study of smoking, caffeine, and alcohol as risk factors for seizures or epilepsy in young adult women: Data from the Nurses' Health Study II. Epilepsia, 51(2), 198-205. http://dx.doi.org/10.1111/j.1528-1167.2009.02268.x 
Esposito, E. M., \& Fitzpatrick, J. J. (2011). Registered nurses' beliefs of the benefits of exercise, their exercise behaviour and their patient teaching regarding exercise. International Journal of Nursing Practice, 17, 351-356. http://dx.doi.org/10.1111/j.1440$172 \times 2011.01951$

Gance, B., Sidora, K., Keesing, H., Gottesman, M. M., \& Brady, M. (2009, July/August). Changes in nurse practitioners' knowledge and behaviors following brief training on the healthy eating and activity together (HEAT) guidelines. Journal of Pediatric Health Care, 23(4), 222-230. http://dx.doi.org/10.1016/j.pedhc.2008.03.002

Grabowska, H., \& Narkiewicz, K. (2013). Nurses' knowledge on the assessment of alcohol consumption and smoking and its effect on blood pressure. Progress in Health Sciences, 3(2), 130-136.

Health Resources and Services Administration. (2013). The U.S. nursing workforce: Trends in supply and education. Retrieved from http://bhpr.hrsa.gov/healthworkforce/reports/nursingworkforce/nursingworkforcefullrepo rt.pdf

Health.gov. (2014). Retrieved October 2014, from http://health.gov/

Hensel, D. (2008). The relationships among health status, healthy lifestyles, and nursing selfconcept among professional nurses (Doctoral dissertation). http://dx.doi.org/10.1177/0193945910373754

Hicks, M., McDermont, L. L., Rouhana, N., Schmidt, M., Seymour, M. W., \& Sullivan, T. (2008). Nurses' body size and public confidence in ability to provide health education. Journal of Nursing Scholarship, 40(4), 349-354. 
Holton, G. (2004). Robert K. Merton: biographical memoirs. Proceedings of the American Philosophical Society, 148(4), 506-517.

Huck, S. W. (2012). Reading statistics and research (6th ed.). Boston, MA: Pearson.

Illingworth, P. (2006). Exploring mental health students' perceptions of role models. British Journal of Nursing, 18(13), 812-815.

Kane, R. L., \& Radosevich, D. M. (2011). Conducting Health Outcomes Research. Sudbury, MA: Jones \& Bartlett Learning.

Kaufman, K. (2007). More findings from the NLN/Carnegie national survey: How nurse educators spend their time. Nursing Education Perspectives, 28(5), 296-297.

Klunkin, A., Sawasdisingha, P., Viseskul, N., Funashima, N., Kameoka, T., Nomoto, Y., \& Nakayama, T. (2011). Role model behaviors of nursing faculty members in Thailand. Nursing and Health Sciences, 13, 84-87. http://dx.doi.org/10.1111/j.14422018.2011.00585.x

Liu, K., Daviglus, M. L., Loria, C. M., Colangelo, L. A., Spring, B., Moller, A. C., \& LloydJones, D. M. (2012). Healthy lifestyle through young adulthood and the presence of low cardiovascular disease risk profile in middle age. Circulation, 125(8), 996-1004. http://dx.doi.org/10.1161/CIRCULATIONAHA.111.060681

Malik, S., Blake, H., \& Batt, M. (2011). How healthy are our nurses? New and registered nurses compared. British Journal of Nursing, 20(8), 489-496. http://dx.doi.org/10.12968/bjon.2011.20.8.489

McKenna, H., Slater, P., McCance, T., Bunting, B., Spiers, A., \& McElwee, G. (2001). Qualified nurses' smoking prevalence: their reasons for smoking and desire to quit. Journal of Advanced Nursing, 35(5), 769-775. http://dx.doi.org/10.1046/j.1365-2648.2001.01909.x 
Melynk, B. M., Hrabe, D. P., \& Szalacha, L. A. (2013). Relationships among work stress, job satisfaction, mental health, and healthy lifestyle behaviors in new graduate nurses attending the nurse athlete program. Nursing Administration Quarterly, 37(4), 278-285. http://dx.doi.org/10.1097/NAQ.0b013e3182a2f963

Miller, S. K., Alpert, P. T., \& Cross, C. L. (2008, March). Overweight and obesity in nurses, advanced practice nurses, and nurse educators. American Academy of Nurse Practitioners, 259-265. http://dx.doi.org/10.1111/j.1745-7599.2008.00319.x

Montoya, P., \& Kozeliski, A. (2014, January, February, March). Nurses and health care reform: Are we leading the way for positive change in our communities? The New Mexico Nurse, 59(1), 7.

Movsisyan, N. K., Varduhi, P., Arusyak, H., Diana, P., Armen, M., \& Frances, S. A. (2012). Smoking behavior, attitudes and cessation counseling among healthcare professionals in Armenia. BMC Public Health, 12, 1-8.

Nurses still at top in trust. (2012). American Nurse, 44(1), 1.

Patra, J., Taylor, B., Irving, H., Roerecke, M., Baliunas, D., Mohapatra, S., \& Rehm, J. (2010). Alcohol consumption and the risk of morbidity and mortality for different stroke types- a systematic review and metanalysis. BMC Public Health, 10, 258-269.

Pender, N. (1996). Health promotion in nursing practice (3rd ed.). Stamford, Conn.: Appleton \& Lange.

Perry, B. (2009). Role modeling excellence in clinical nursing. Nurse Education in Practice, 9, 36-44. http://dx.doi.org/10.1016/j.nepr.2008.05.001 
Petch-Levine, D., Cureton, V. Y., Canham, D., \& Murray, M. (2003, October 1). Health practices of school nurses. The Journal of School Nursing, 19(5), 273-280. http://dx.doi.org/10.1177/10598405030190050501

Poli, A., Marangoni, F., Avogaro, A., Barba, G., Bellentani, S., Bucci, M., ... Visioli, F. (2013). Moderate alcohol use and health: A consensus document. Nutrition, Metabolism \& Cardiovascular Diseases, 23, 487-504. http://dx.doi.org/10.1016/j.numecd.2013.02.007

Popplewell, P. (2006). The advanced practice nurse is a role model. AACN News, 23(4), 5-6.

President's Council on Fitness, Sports \& Nutrition website. (n.d.). Retrieved October 2014, from http://www.fitness.gov/be-active/physical-activity-guidelines-for-americans/

Roux, G., DiMarco, N., Gu, Y., Ballard, E., Scott, S., Ellison, A., \& Efesoa, M. A. (2013, January-March). Eating, activity, and supportive environment (EASE) for nursing students. Nursing Forum, 49(1), 49-58.

Rush, K. L., Kee, C. C., \& Rice, M. (2005). Nurses as imperfect role models for health promotion. Western Journal of Nursing Research, 27(2), 166-183.

Rush, K. L., Kee, C. C., \& Rice, M. (2010, May 6). The self as role model in health promotion scale: Development and testing. Western Journal of Nursing Research, 32(6), 814-832. http://dx.doi.org/10.1177/0193945910361595

Sarna, L., Bialous, S. A., Nandy, K., Antonio, A. M., \& Yang, Q. (2014, January 8). Changes in smoking prevalences among health care professionals from 2003 to 2010-2011. Journal of the American Medical Association, 311(2), 197-199. 
Sarna, L., Bialous, S. A., Nandy, K., \& Yang, Q. (2012). Are quit attempts among U.S. female nurses who smoke different from female smokers in the general population? An analysis of the 2006/2007 tobacco use supplement to the current population survey. BioMed Central, 12(4). Retrieved March 2015, from http://www.biomedcentral.com/1472$6874 / 12 / 4$

Sharma, M. (2005). Enhancing the effectiveness of alcohol and drug education programs through social cognitive theory. Journal of Alcohol and Drug Education, 49(3), 3-7.

Slater, P., McElwee, G., Flemming, P., \& McKenna, H. (2006, May 9). Nurses' smoking behaviour related to cessation practice. Nursing Times, 102(19), 32-37.

Smith, L. P., Ng, S. W., \& Popkin, B. M. (2013). Trends in US home food preparation and consumption: Analysis of national nutrition surveys and time from 1965-1966 to 20072008. Nutrition Journal, 12(45).

TN Department of Health. (n.d.). Smokefree Tennessee: Tennessee Non-Smokers Protection Act. Retrieved March 2015, from http://tn.gov/health/topic/smokefree-tennessee Tennessee Board of Nursing. (2014). Newsletter. Tennessee Board of Nursing Newsletter, 5(1), 1-12. Retrieved from http://health.state.tn.us/Boards/Nursing/PDFs/TBN_Fall_2014.pdf

Thomas, J. R., \& Nelson, J. (2001). Research methods in physical activity (4th ed.). Champaign, IL: Humanics Kinetics.

Trust for America's Health and Robert Wood Johnson Foundation. (2014). The state of obesity 2014. Retrieved March 2015, from http://stateofobesity.org/states/tn/

Tucker, S. J., Harris, M. R., Pipe, T. B., \& Stevens, S. R. (2010). Nurses' ratings of their health and professional work environments. American Association of Occupational Health Nurses, 58(6), 253-267. http://dx.doi.org/10.3928/08910162-20100526-03 
U.S. Department of Agriculture and U.S. Department of Health and Human Services. (2010). Dietary guidelines for Americans, 2010. Retrieved March 2015, from Www.dietaryguidelines.gov

Wang, L., Lee, I., Manson, J., Buring, J., \& Sesso, H. (2010). Alcohol consumption, weight gain, and risk of becoming overweight in middle-aged and older women. Archives Internal Medicine, 170(5), 453-461.

West Virginia Department of Health and Human Resources. (n.d.). Obesity: facts, figures, guidelines. Retrieved October 2014, from http://www.wvdhhr.org/bph/oehp/obesity/mortality.htm

Whitehead, D. (2001). Health education, behavioral change and social psychology: Nursing's contribution to health promotion. Journal of Advanced Nursing, 34(6), 822-832.

Willaing, I., Jorgensen, T., \& Iversen, L. (2003). How does individual smoking behaviour among hospital staff influence their knowledge of the health consequences of smoking? Scandinavian Journal of Public Health, 31, 149-155. http://dx.doi.org/10.1080/14034940210164876

Willaing, I., \& Ladelund, S. (2004, April). Smoking behavior among hospital staff still influences attitudes and counseling on smoking. Nicotine \& Tobacco Research, 6(2), 369-375. http://dx.doi.org/10.1080114622200410001676422

World Health Organization. (1986). The Ottawa Charter for health promotion. Retrieved October 2014, from http://www.who.int/healthpromotion/conferences/previous/ottawa/en/ World Health Organization. (2003). Retrieved October 2014, from http://www.who.int/about/definition/en/print.html 
Yancey, A. K., Grant, D., Kurosky, S., Kravitz-Wirtz, N., \& Mistry, R. (2011). Role modeling, risk, and resilience in California adolescents. Journal of Adolescent Health, 48(1), 36-43. http://dx.doi.org/doi:10.1016/j.jadohealth.2010.05.001

Zitkus, B. S. (2011). The relationship among registered nurses' weight status, weight loss regimens, and successful or unsuccessful weight loss. Journal of the American Academy of Nurse Practitioners, 23, 110-116. http://dx.doi.org/10.1111/j.1745-7599.2010.00583.x 


\section{APPENDICES}

APPENDIX A

\section{Demographic Information}

1. What is your current age?

2. What is your gender? Female Male

3. What is your ethnic group?

Caucasian African American

Hispanic American Indian

Asian Pacific Islander

Other (specify)

4. Which region of Tennessee do you live in?

East

Middle

West

5. Which area do you live in?

Rural

Urban

Suburban 
6. Which of the following degrees do you hold? (Please check all that apply) Diploma in Nursing

Associate in Nursing

BSN

MSN

$\mathrm{PhD}$ in Nursing

DNP

Other (specify)

7. How long have you been a nurse?

8. What is your area of employment?

Acute Care

Ambulatory Care

Community

Long term Care

Home Health/ Hospice School

College/Academia Industry

Private Practice Other (Specify)

9. What is your approximate household income?

Under 50,000

$50,000-60,000$

$61,000-70,000$

$71,000-80,000$

$81,000-90,000$

$91,000-100,000$ 
Over 100,000

10. On average, how many packs of cigarettes do you smoke each DAY? Enter 0 if you do not smoke.

A standard drink contains 0.6 ounces of pure alcohol, for example, 12-ounces beer, 80ounces malt liquor, 5-ounces of wine, or 1.5 ounces of 80-proof distilled spirits.

11. On average, how much do you drink each DAY?

A healthy diet is defined as eating more fruits, vegetables, whole grains, seafood, and choose fat-free and low-fat dairy while decreasing salt and foods high in sodium, saturated fats, trans-saturated fats, cholesterol, added sugar, and refined grains.

12. On a scale of 1-10 (with 1 being not very likely and 10 being always) How faithfully do you follow the guidelines for a healthy diet?

Moderate physical activity is defined as a target heart rate 50 to $70 \%$ above the individual's maximum heart rate. Examples of moderate activity include brisk walking and water aerobics.

13. On average, how many minutes of moderate exercise do you do each week?

14. What is your weight in pounds?

15. What is your height? feet inches 


\section{APPENDIX B}

\section{The Self as Role Model in Health Promotion}

In this survey you are asked to rate a series of items about how you see yourself as a role model of health. Because your ratings represent your personal view of yourself as a role model of health, no definition of the term "role model of health" has been provided. Read each item and decide whether you agree or disagree and to what extent. If you strongly agree, circle 6; if you strongly disagree, circle 1 ; if you view yourself somewhere in between, circle any one of the numbers between 1 and 6 . Some of the items may not seem to relate to being a role model of health but please answer as best as you can anyway.

$$
\begin{array}{lll}
1=\text { Strongly Disagree } ; & 2=\text { Moderately Disagree } ; & 3=\text { Slightly Disagree } ; \\
4=\text { Slightly Agree } ; & 5=\text { Moderately Agree } ; & 6=\text { Strongly Agree }
\end{array}
$$

*1. I feel a lot of pressure from others to be a role model of healthy behaviors

2. I practice healthy behaviors exclusively for my own personal well-being

3. I am always honest with clients about the struggles involved in trying to practice a healthy lifestyle

4. I begin with clients' own experiences in guiding them with their health promoting efforts

*5. To be a role model of health promotion I must consistently attain a high standard of healthy behaviors

*6. I have to be knowledgeable about health related issues because others expect it of me

7. I direct clients in a variety of positive directions that I think will make health promoting changes

8 . To be a role model of health promotion I must be up on a pedestal

*9. I feel a lot of guilt when I teach about health behaviors I am not practicing $\begin{array}{llllll}1 & 2 & 3 & 4 & 5 & 6\end{array}$

$\begin{array}{llllll}1 & 2 & 3 & 4 & 5 & 6\end{array}$

$\begin{array}{llllll}1 & 2 & 3 & 4 & 5 & 6\end{array}$

$\begin{array}{llllll}1 & 2 & 3 & 4 & 5 & 6\end{array}$

$\begin{array}{llllll}1 & 2 & 3 & 4 & 5 & 6\end{array}$

$\begin{array}{llllll}1 & 2 & 3 & 4 & 5 & 6\end{array}$

$\begin{array}{llllll}1 & 2 & 3 & 4 & 5 & 6\end{array}$

$\begin{array}{llllll}1 & 2 & 3 & 4 & 5 & 6\end{array}$

$\begin{array}{llllll}1 & 2 & 3 & 4 & 5 & 6\end{array}$ 
10. I practice a healthy lifestyle as part of who

I am as a person

11. I listen to what clients perceive as their needs

$* 12$. To be a role model of health promotion

I must set an ideal standard for others to

strive for

*13. I have to practice a healthy lifestyle

because others expect me to

14. I always take time to understand why a

client's lifestyle is the way it is

15. I always consider clients' socio-economic situation when working with them around health-related issues

16. To be a role model of health promotion I should be seen as a human being with struggles

17. I have made positive health changes that have helped me connect with clients making similar changes

*18. Others expect me as a nurse to be a role model of health promotion regardless of how I see myself

19. I am going in the direction that I want to be with my personal health practices

20. I help clients understand lifestyle changes so they can incorporate them into their lives

21. I convey to clients that I am a human being with weaknesses

22. I practice a healthy lifestyle because I am a nurse $\begin{array}{llllll}1 & 2 & 3 & 4 & 5 & 6\end{array}$

$\begin{array}{llllll}1 & 2 & 3 & 4 & 5 & 6\end{array}$

$\begin{array}{llllll}1 & 2 & 3 & 4 & 5 & 6\end{array}$

$\begin{array}{llllll}1 & 2 & 3 & 4 & 5 & 6\end{array}$

$\begin{array}{llllll}1 & 2 & 3 & 4 & 5 & 6\end{array}$

$\begin{array}{llllll}1 & 2 & 3 & 4 & 5 & 6\end{array}$

$\begin{array}{llllll}1 & 2 & 3 & 4 & 5 & 6\end{array}$

$\begin{array}{llllll}1 & 2 & 3 & 4 & 5 & 6\end{array}$

$\begin{array}{llllll}1 & 2 & 3 & 4 & 5 & 6\end{array}$

$\begin{array}{llllll}1 & 2 & 3 & 4 & 5 & 6\end{array}$

$\begin{array}{llllll}1 & 2 & 3 & 4 & 5 & 6\end{array}$

$\begin{array}{llllll}1 & 2 & 3 & 4 & 5 & 6\end{array}$

$\begin{array}{llllll}1 & 2 & 3 & 4 & 5 & 6\end{array}$ 
23. I strongly encourage clients to enhance their own health

*24. I feel guilty when others see I am not practicing what I preach

25. I give clients information to make their own decisions

26. I work in partnership with clients to promote their health

*27. I think of myself more as a health promoter than a role model because promoting health is what I do

*28. I must readily give health information because others expect it of me

29. I accept that I am an imperfect example of healthy behaviors

30. I always help clients understand lifestyle changes for them personally

31. I have had clients identify with me because like them, I have had similar struggles with changing my health practices

32. To be a role model of health promotion I should be myself with others

*33. I must "practice what I preach" because others expect it of me

34. I look at the whole of clients' lives when helping them with health promotion

$* 35$. To be a role model of health promotion I must always reach for the ideal

36. I understand what a client is going through in making lifestyle changes because of my own personal struggles $\begin{array}{llllll}1 & 2 & 3 & 4 & 5 & 6\end{array}$

$\begin{array}{llllll}1 & 2 & 3 & 4 & 5 & 6\end{array}$

$\begin{array}{llllll}1 & 2 & 3 & 4 & 5 & 6\end{array}$

$\begin{array}{llllll}1 & 2 & 3 & 4 & 5 & 6\end{array}$

$\begin{array}{llllll}1 & 2 & 3 & 4 & 5 & 6\end{array}$

$\begin{array}{llllll}1 & 2 & 3 & 4 & 5 & 6\end{array}$

$\begin{array}{llllll}1 & 2 & 3 & 4 & 5 & 6\end{array}$

$\begin{array}{llllll}1 & 2 & 3 & 4 & 5 & 6\end{array}$

$\begin{array}{llllll}1 & 2 & 3 & 4 & 5 & 6\end{array}$

$\begin{array}{llllll}1 & 2 & 3 & 4 & 5 & 6\end{array}$

$\begin{array}{llllll}1 & 2 & 3 & 4 & 5 & 6\end{array}$

$\begin{array}{llllll}1 & 2 & 3 & 4 & 5 & 6\end{array}$

$\begin{array}{llllll}1 & 2 & 3 & 4 & 5 & 6\end{array}$

$\begin{array}{llllll}1 & 2 & 3 & 4 & 5 & 6\end{array}$ 
*37. To be a role model of health promotion

$\begin{array}{llllll}1 & 2 & 3 & 4 & 5 & 6\end{array}$

I must assume professional responsibility

to practice a healthy lifestyle

*38. I feel like a role model when people ask me for health-related information

*39. I generally give little thought to my health behaviors

40. I find out clients' perceptions of their health practices

41. I do something when I fall short in my personal health practices

$\begin{array}{llllll}1 & 2 & 3 & 4 & 5 & 6\end{array}$

$\begin{array}{llllll}1 & 2 & 3 & 4 & 5 & 6\end{array}$

$\begin{array}{llllll}1 & 2 & 3 & 4 & 5 & 6\end{array}$

$\begin{array}{llllll}1 & 2 & 3 & 4 & 5 & 6\end{array}$

42. I explore various options with clients in guiding their decision-making about health practices

43. I am okay with doing my best to role model a healthy lifestyle even though I am not perfect

44. I prefer to be called a health promoter rather than a role model

45. I respect when clients are not ready to make health promoting changes

46. I work with clients at finding solutions to their health-related situations and problems

47. Health promoter describes what I do better than role model

*48. I feel like I have to practice a healthy lifestyle because others are watching me

49. I accept that my personal health practices are less than perfect

50. I simplify health-related information to make it useful for clients

$\begin{array}{llllll}1 & 2 & 3 & 4 & 5 & 6\end{array}$

$\begin{array}{llllll}1 & 2 & 3 & 4 & 5 & 6\end{array}$

$\begin{array}{llllll}1 & 2 & 3 & 4 & 5 & 6\end{array}$

$\begin{array}{llllll}1 & 2 & 3 & 4 & 5 & 6\end{array}$

$\begin{array}{llllll}1 & 2 & 3 & 4 & 5 & 6\end{array}$

$\begin{array}{llllll}1 & 2 & 3 & 4 & 5 & 6\end{array}$

$\begin{array}{llllll}1 & 2 & 3 & 4 & 5 & 6\end{array}$

$\begin{array}{llllll}1 & 2 & 3 & 4 & 5 & 6\end{array}$

$\begin{array}{llllll}1 & 2 & 3 & 4 & 5 & 6\end{array}$ 
*51. To be a role model of health promotion I have to live up to the ideal

52. I respect that people are at different places in their health promoting efforts

53. I think that as a health promoter I am a role model

*54. I must be accountable for modeling health promotion in both my personal and professional life

55. I individualize health related information for the client

56. I give clients complete control in making decisions about their health

57. I am accepting of clients who continue in unhealthy practices $\begin{array}{llllll}1 & 2 & 3 & 4 & 5 & 6\end{array}$

$\begin{array}{llllll}1 & 2 & 3 & 4 & 5 & 6\end{array}$

$\begin{array}{llllll}1 & 2 & 3 & 4 & 5 & 6\end{array}$

$\begin{array}{llllll}1 & 2 & 3 & 4 & 5 & 6\end{array}$

$\begin{array}{llllll}1 & 2 & 3 & 4 & 5 & 6\end{array}$

$\begin{array}{llllll}1 & 2 & 3 & 4 & 5 & 6\end{array}$

$\begin{array}{llllll}1 & 2 & 3 & 4 & 5 & 6\end{array}$

Overall as a role model of health, I am (check 1):

5. Very Poor
4. Poor
3. Fair
2. Good
1. Very Good

Thank you very much for taking the time to answer these questions! 


\title{
APPENDIX C
}

\author{
Recruitment Email
}

\section{Dear Participant:}

My name is Shelia Hurley, and I am a graduate student at East Tennessee State University. I am working on my PhD in Nursing. In order to finish my studies, I need to complete a research project. The name of my research study is Nurses Perceptions of Self as Role Models of Health.

The purpose of this study is to determine the nurses' perception of the role of the nurse in health promotion and what health behaviors nurses portray to their patients. I would like to give a brief survey questionnaire to Registered Nurses. It should only take about 30 minutes to complete. You will be asked questions about yourself as a role model and your health practices.

This method is completely anonymous and confidential. In other words, there will be no way to connect your name with your responses. Although your rights and privacy will be maintained, the Secretary of the Department of Health and Human Services, the ETSU IRB and the researcher have access to the study records.

Participation in this research experiment is voluntary. You may refuse to participate. You can quit at any time. Participants must be 18 or older to take part.

Once you have completed the survey, you will have an option to follow a separate link to enter a drawing for a $\mathbf{\$ 5 0}$ gift card. Two gift cards will be given away at the end of the research study. If you are the winner of a gift card, you will have to provide additional information such as name, address and social security number to receive the gift.

To take the survey Please follow the link below:

\section{Link will be insert here}

Thank you very much for taking the time to participate in this study. If you have any researchrelated questions or problems, you may contact me at 423-439-4055. I am working on this project under the supervision of Joellen Edwards. You may reach her at 423-439-4055. Also, the chairperson of the Institutional Review Board at East Tennessee State University is available at (423) 439-6054 if you have questions about your rights as a research subject. If you have any questions or concerns about the research and want to talk to someone independent of the research team or you can't reach the study staff, you may call an IRB Coordinator at 423/439-6055 or 423/439/6002.

Sincerely,

Shelia Hurley $\mathrm{PhD}(\mathrm{c}), \mathrm{MSN}, \mathrm{RN}, \mathrm{MBA} / \mathrm{HC}$ 


\section{APPENDIX D \\ Recruitment Reminder Email}

\section{Dear Participant:}

\section{This is a reminder email to complete a survey for a chance to win $\$ \mathbf{5 0 . 0 0}$}

My name is Shelia Hurley, and I am a graduate student at East Tennessee State University. I am working on my PhD in Nursing. In order to finish my studies, I need to complete a research project. The name of my research study is Nurses Perceptions of Self as Role Models of Health.

The purpose of this study is to determine the nurses' perception of the role of the nurse in health promotion and what health behaviors nurses portray to their patients. I would like to give a brief survey questionnaire to Registered Nurses. It should only take about 30 minutes to complete. You will be asked questions about yourself as a role model and your health practices.

This method is completely anonymous and confidential. In other words, there will be no way to connect your name with your responses. Although your rights and privacy will be maintained, the Secretary of the Department of Health and Human Services, the ETSU IRB and the researcher have access to the study records.

Participation in this research experiment is voluntary. You may refuse to participate. You can quit at any time. Participants must be 18 or older to take part.

Once you have completed the survey, you will have an option to follow a separate link to enter a drawing for a $\mathbf{\$ 5 0}$ gift card. Two gift cards will be given away at the end of the research study. If you are the winner of a gift card, you will have to provide additional information such as name, address and social security number to receive the gift.

To take the survey Please follow the link below:

\section{Link will be insert here}

Thank you very much for taking the time to participate in this study. If you have any researchrelated questions or problems, you may contact me at 423-439-4055. I am working on this project under the supervision of Joellen Edwards. You may reach her at 423-439-4055. Also, the chairperson of the Institutional Review Board at East Tennessee State University is available at (423) 439-6054 if you have questions about your rights as a research subject. If you have any questions or concerns about the research and want to talk to someone independent of the research team or you can't reach the study staff, you may call an IRB Coordinator at 423/439-6055 or 423/439/6002.

Sincerely,

Shelia Hurley PhD(c), MSN, RN, MBA/HC 
Education:

\section{Professional Experience:}

Publications:

Presentations:
$\mathrm{PhD}$ in Nursing, East Tennessee State University, Johnson City, Tennessee 2015

MSN/MBA HC, University of Phoenix, Phoenix, Arizona, 2009

B.S. Nursing, Tennessee Tech University, Cookeville, Tennessee, 1994

Assistant Professor, Tennessee Tech University, WhitsonHester School of Nursing, 2010-current

Hanna, K., Roberts, T., Hurley, S. (In Press). Collaborative Testing as NCLEX-RN Enrichment. Nurse Educator.

Hellman, A., Woodard, W., Hurley, S. (October/December, 2015). Nurses and their knowledge of spiritual needs: A study using the spiritual care competency scale. Journal of Christian Nursing. 32(4) 236-241. 10.1097/CNJ.0000000000000207

Hurley, S. \& Piras, S. (November/December 2012). Cushing disease: Is it a disease, a syndrome, or both? Nursing made Incredibly Easy! 10(6), 38-46. 10.1097/01.NME.0000420368.31717.c1.

Hurley, S. (June 11, 2015). Nurses' Perception as Role Models of Health Promotion. In the proceedings of and oral presentation at 2nd Canadian Doctoral Nursing Network Conference held at the University of Regina, Saskatchewan, Canada on June 11-12, 2015.

Hellman, A., Hurley, S., Turpin, R., and Hanna, K. (October 2015) Prepping the Drivers of the Future: Enhancing Practice Readiness through Collaborative Interventional Learning Simulation. The 42nd Annual Professional Nurse Educators Group (PNEG) conference. Indianapolis, IN.

Hurley, S. (June 2015). Nurses' Perception as Role Models of Health Promotion. Accepted for podium presentation at the 2nd Canadian Doctoral Nursing Network Conference held at the University of Regina, Saskatchewan, Canada on June 11-12, 2015. 
Hellman, Hurley, S. \& Lee, E (February 2014). Anchor your students into Generating New Knowledge using the Lab Link Assessment Strategy. Accepted for poster presentation at the $28^{\text {th }}$ annual Southern Nursing Research Society, Enhancing Value-based care: Generating New Knowledge, held in San Antonio, Texas, February 12-14, 2014.

Hurley, S. (January $\left.17^{\text {th }}, 2014\right)$. Residency Experiences to Support Scholarship and Professionalism through the Doctoral Journey. Research Colloquium; East Tennessee State University.

Hurley, S. (October $\left.11^{\text {th }}, 2013\right)$. Review of the Timeline of Obese Trends with Political and Agricultural Movements. Guest lecture for NURS 4990 Special Topics (face-to-face) offered at Whitson-Hester School of Nursing, Tennessee Tech University. Instructor: Assistant Professor Rachel Hall.

Hurley, S. (April $\left.5^{\text {th }}, 2013\right)$. Obesity Trends. Guest lecture for NURS 4990 Special Topics (face-to-face) offered at Whitson-Hester School of Nursing, Tennessee Tech University. Instructor: Assistant Professor Rachel Hall. 